\title{
Synthesis of Semiochemicals via Olefin Metathesis
}

\author{
Gábor Turczel, ${ }^{1}$ Ervin Kovács, ${ }^{l}$ Gabriella Merza, ${ }^{1}$ Philip Coish,${ }^{2}$ Paul T. Anastas, ${ }^{2 *}$ Robert
}

$T u b a^{1 *}$

${ }^{1}$ Institute of Materials and Environmental Chemistry, Research Centre for Natural Sciences, Hungarian Academy of Sciences, Magyar tudósok körútja 2., 1519 Budapest, P.O. Box 286.

Hungary

${ }^{2}$ Center for Green Chemistry and Engineering, Yale University, 225 Prospect Street, Kline Chemistry 207, New Haven, CT 06520, USA.

*Email: tuba.robert@ttk.mta.hu,paul.anastas@yale.edu

KEYWORDS. Semiochemicals, biopesticides, olefin metathesis, catalysis, green chemistry

ABSTRACT. Semiochemicals are substances or mixtures that carry messages and are used for communication between individuals of the same or different species. Semiochemicals that are used in pest control are called biopesticides. Conventional pesticides, which are generally synthetically derived and unnatural, inactivate or kill the pests, whereas biopesticides are naturally occurring compounds that attract insects to a trap or interfere with their reproduction. There are several advantages to biopesticides. Compared to conventional pesticides, biochemical-based pesticides are often less toxic and therefore pose a significantly lower impact 
on human health and the environment. Moreover, the biopesticides are pest selective and as such, do not negatively impact other organisms such as insects, mammals or birds. Other advantages of biopesticides include high potency, meaning that smaller amounts of biopesticide are required, less resistance by target organisms, and the ability to biodegrade more quickly than conventional pesticides.--3 Although the biochemical-based pesticides are very promising materials, their production is often cumbersome and their application is often limited. So far, most of the biopesticides are synthesized by multistep, classical organic reactions which are not economical and pose high environmental impact. However, in recent decades, many efforts have been done to implement cost-effective and safer chemical procedures for the widespread application of biochemical-based pesticides. The purpose of this perspective is to draw the attention of the green chemistry community to the applicability of olefin metathesis reactions in environmental benign and cost-effective biopesticide synthesis. In this article, we review seminal work on the total synthesis of biopesticides using olefin metathesis as a key reaction step, and in doing so, we hope to inspire new ideas for forthcoming olefin metathesis based biopesticide development.

\section{Introduction}

One of the most widely used biochemical pesticides are insect pheromones. The pheromones are biochemicals which are excreted by insects and able to trigger a social response. In general, the pheromones can be categorized as sex, territorial, signal, epideictic, aggregation, alarm, releaser, primer, and trail pheromones. ${ }^{4}$ From the point of pest control, the naturally occurring insect sex and aggregating pheromones are important classes of biochemical pesticides. These compounds can be used to regulate insect pests by non-toxic mechanisms and 
pose no risk to human health. They can be used as attractants (trapping mode) where the bait (a pheromone containing mixture) has to mirror the female scent exactly to capture males. The presence of isomeric impurities, at levels as low as $0.1 \%$, could have an adverse effect on the effectiveness of the bait. On the other hand, pheromones can be applied to disrupt mating and thus disrupt insect reproduction. In this method, a larger amount of biopesticide is applied to the agricultural fields in order to confuse mating pests by overloading their sensory receptors. ${ }^{5,6}$ This technique does not require ultra-pure components and can be successful with a mixture of stereoisomers.

Although the biochemical-based pesticides are very promising as sustainable materials, their production is not cost effective and consequently their market price is not competitive with other commercially available, synthetic pesticides. The synthesis of pheromones with classical organic preparation techniques is often cumbersome, it is neither economically profitable nor environmentally benign. However, in recent decades, there has been considerable effort to develop cost-effective and safer, synthetic routes to naturally occurring pesticides.

The olefin metathesis reaction has become an important method within industry and its use has produced innovative materials, petrochemicals and pharmaceuticals. ${ }^{7,8}$ In 2005 , the Nobel Prize in Chemistry was awarded to the three chemists who were involved with the discovery of novel catalysts for the metathesis reaction and the elucidation the reaction mechanism. The application of metathesis reactions within the field of green chemistry is emerging, ${ }^{9}$ and notably, the application of olefin metathesis reactions to biopesticide synthesis is receiving much attention.

The word "metathesis" is from the Greek meaning "change of position" or "transposition." During olefin metathesis reactions, two $\mathrm{C}=\mathrm{C}$ double bonds are reorganized to 
form two new $\mathrm{C}=\mathrm{C}$ double bonds with an exchange of the olefin substituents (Scheme 1$)$. The reaction is catalyzed by an organometallic species, which, in earlier protocols, was formed in situ from multiple components. The industrial application of metathesis reactions beyond the petroleum industry became viable when stable, highly efficient and well-defined systems were available.

A wide range of catalysts has been shown to initiate metathesis reactions. Catalysts are mostly derived from high oxidation state transition metal halides $\left(\mathrm{MoCl}_{5}, \mathrm{WCl}_{6}\right)$ and main group metal alkyl co-catalyst $\left(\mathrm{AlEt}_{3}, \mathrm{SnBu}_{4}\right) .{ }^{10}$ The most active and widely used catalysts are molybdenum and ruthenium based systems. The molybdenum-based systems ${ }^{11,12}$ are sometimes more active than the ruthenium systems; however, they usually suffer from high oxygen and moisture sensitivity. Therefore, their industrial and large-scale applications are often limited. Recent efforts have led to the formulation of molybdenum catalysts with paraffin-wax, ${ }^{13}$ which increased their stability and ease of handling outside of a glovebox. This formulation could potentially expand their industrial relevance. ${ }^{14}$ On the other hand being more stable to water and oxygen, the ruthenium catalyst systems have a high functional group tolerance. ${ }^{15,16}$

Scheme 1. The four classes of olefin metathesis reactions 


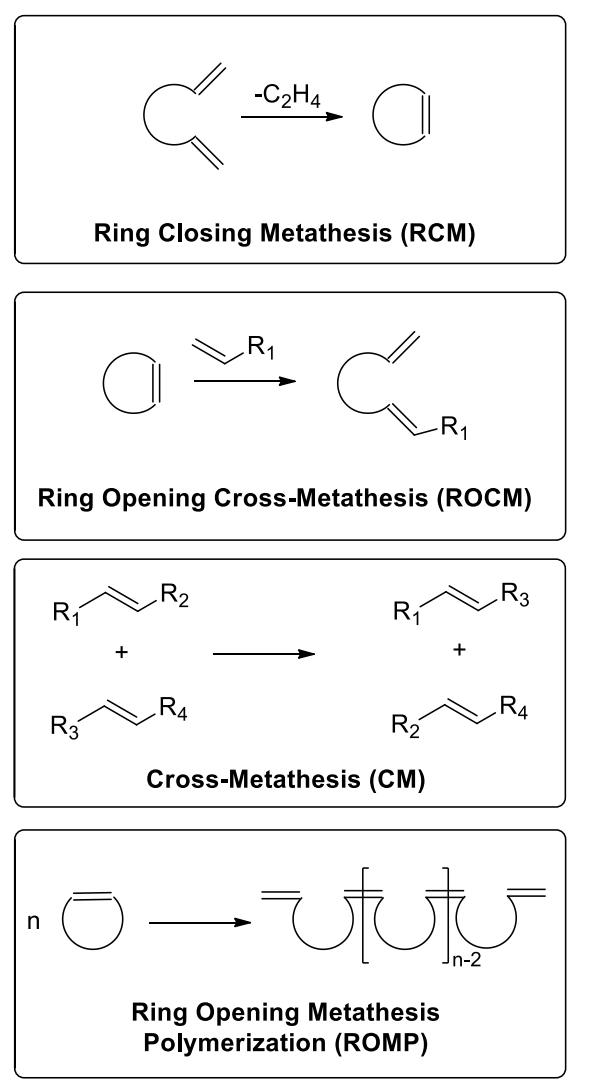

The development of highly active catalyst systems is relevant not only from an economical but green chemistry point of view. Highly active catalytic systems require less energy and lower catalyst loading making chemical conversions even more environmentally benign, in addition to cost-effective. Indeed, the application of catalysis to chemical synthesis is in accordance with the Principles of Green Chemistry. ${ }^{17}$ This is especially true for metathesis where the atom economy of the reactions may reach 100\% in reactions such as ROCM and ROMP. Therefore, the application of metathesis chemistry in the valorization of sustainable feedstock materials is an excellent strategy for the development of green and sustainable chemical technologies. Consequently, the synthesis of insect pheromones using olefin metathesis is an emerging area. In this review, we summarize the pioneering work and achievements in the total synthesis of semiochemicals using olefin metathesis as a key reaction step. 


\section{Pheromone synthesis via cross-metathesis (CM)}

Many of the insect pheromones are long chained, unsaturated hydrocarbon derivatives, which can be originated from fatty alcohols. ${ }^{18}$ Although many of them are relatively simple molecules, their synthesis is often cumbersome due to the well-defined number, position and the stereochemistry of the unsaturated bonds. The classical routes to produce these compounds involved Wittig reactions that generate a large amount of phosphine-oxide waste from the stoichiometric ylide reagent. ${ }^{19}$ An alternative and an environmentally benign synthetic procedure is the usage of the cross-metathesis $(\mathbf{C M})$ reactions using renewable starting materials, including plant oils (palm, rapeseed, and soybean). ${ }^{20-26}$ Since the discovery of stereoselective ( $Z$ and $E$ selective) metathesis catalyst systems, the application of $\mathbf{C M}$ reactions in pheromone synthesis has become more attractive and more commonplace.

\section{Early Mo and W examples}

Early CM examples ${ }^{27,28}$ (Scheme 2) predominately used ill-defined, homogeneous Fischer-type carbene tungsten ${ }^{29-31}$ or heterogeneous molybdenum ${ }^{32-36}$ catalytic systems. Most require toxic tin compounds as co-catalysts or promoters, which makes them potentially hazardous for human health and the environment. Typically, the E-olefin isomers were isolated as the major products. For example, the olefin metathesis of 1-hexene (4) with ethyl oleate (EO) using molybdenum as catalyst provided an 82:18 mixture of $E: Z$ isomers, with the $E$-olefinic ester (5) as the major product (Scheme 2). ${ }^{35}$

Scheme 2. Early pheromone metathesis examples $(\mathbf{E O}=$ ethyl oleate $)$ 


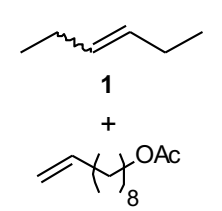

2

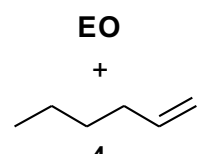

4
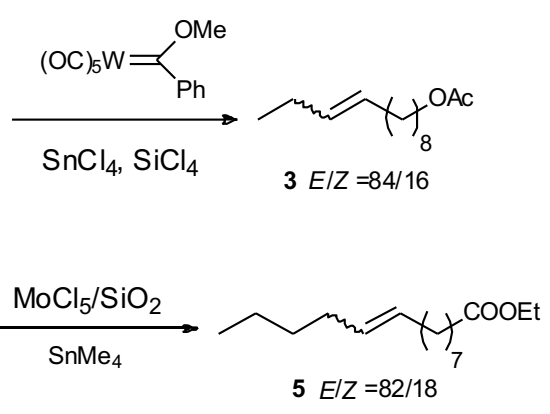

\section{Ru-alkylidenes}

The discovery of ruthenium-based metathesis catalyst systems (Scheme 3) opened a new era for the synthesis of pheromones having a wide range of functionalities. Due to the higher stability, functional group tolerance, and lower air and water sensitivity as compared to the molybdenum-based systems, ruthenium-based metathesis catalysts employing Grubbs catalysts have become dominant in the industrial applications of the olefin metathesis. The so-called second generation Grubbs- and Hoveyda-Grubbs catalysts (e.g., G-2, HG-2) are in general more active than the first generation one (e.g., G-1) ${ }^{37}$ Using these catalysts, a high conversion of renewable feedstock including vegetable oils into value-added chemicals such as biopesticides can be achieved.

Scheme 3. Grubbs catalysts for ruthenium-based olefin metathesis reaction (Mes $=2,4,6$ trimethylbenzene)

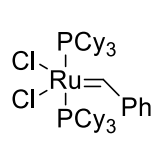

G-1

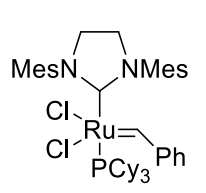

G-2

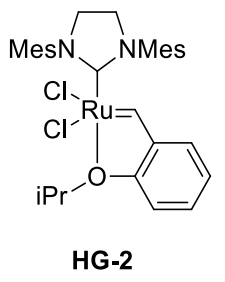

Scheme 4. Synthesis of the pheromone of Anarsia lineatella (8) from terminal alkenes 


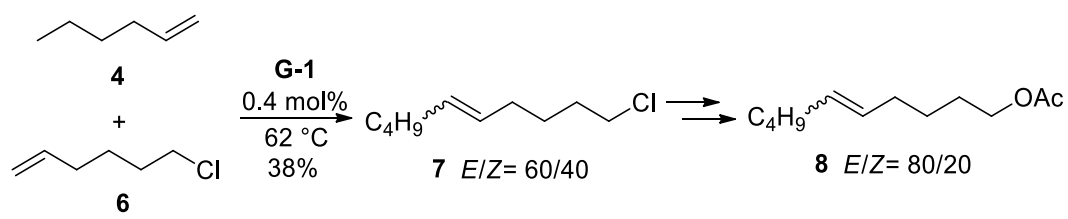

The synthesis of 5-decenyl acetate (8), the sex pheromone of peach twig borer (Anarsia lineatella), is one of the most extensively studied $\mathbf{C M}$ reactions (Scheme 4). ${ }^{38,39}$ An example is the reaction of 1-chloro-5-hexene (6) and 1-hexene (4) in the presence of Grubbs catalyst, G-1, which provided the desired olefin 8 as an $80 / 20$ mixture of $E / Z$ isomers, respectively. The use of $\alpha$-alkene 4 led to the formation of the sensitive Ru-methylidene species. However, the application of an internal alkene, 5-decene (10) instead, avoided the formation of the undesired Ru-methylidene intermediate and significantly increased the overall yield of 8 to $87 \%$ (Scheme 5). ${ }^{39}$

Scheme 5. Synthesis of the pheromone of Anarsia lineatella (8) from internal alkene $\mathbf{9}$ and $\mathbf{1 0}$

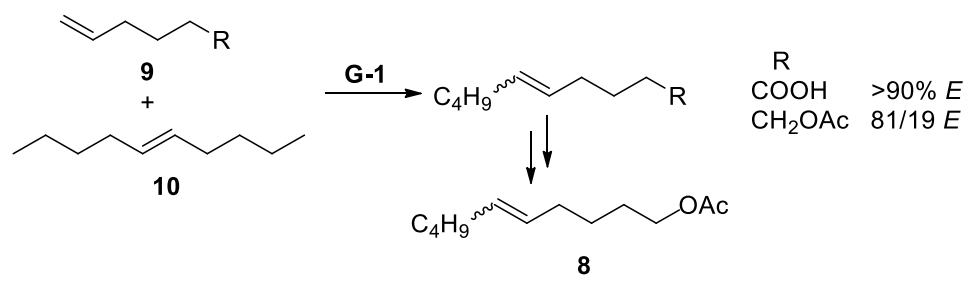

The use of symmetric, unsaturated diacetate, $\mathbf{1 1}$ and low temperature $\left(5^{\circ} \mathrm{C}\right)$ gave $\mathbf{8}$ as a mixture of $E / Z$ isomers (Scheme 6). A typical side reaction of ruthenium initiated olefin metathesis is double bond migration within the product, but under these conditions, the formation of sideproduct was negligible (less than $0.1 \%$ ). This is highly important and should be considered, as the undesired isomers can have a negative impact on the effectiveness of the pheromone as a biopesticide. $^{40,41}$

Scheme 6. Synthesis of pheromone of Anarsia lineatella $\mathbf{8}$ by cross-metathesis of internal alkenes 


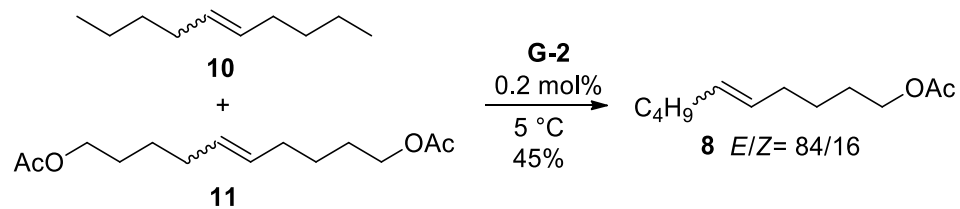

Another highly relevant example of this discussion is the synthesis of omnivorous leafroller's (Platynota stultana) pheromone (14)..$^{38,39,42}$ Three synthetic routes to $\mathbf{1 4}$ that involve olefin metathesis as a key reaction step are shown in Scheme 7. In the first example, the metathesis reaction of 1-butene (12) and acetate $\mathbf{1 3}$ using Grubb's catalyst G-1 provided the pheromone $\mathbf{1 4}$ as a mixture of $E / Z$ isomers. Notably, the metathesis of compounds $\mathbf{1 5}$ and $\mathbf{1 6}$ with $\mathbf{G - 2}$ provided an isomeric mixture of the pheromone in a ratio similar to that of the naturally-occurring mixture $(E / Z=82 / 18) \cdot{ }^{43}$

Scheme 7. Three different routes to E-9-decenyl-acetate (14), the pheromone of Platynota stultana

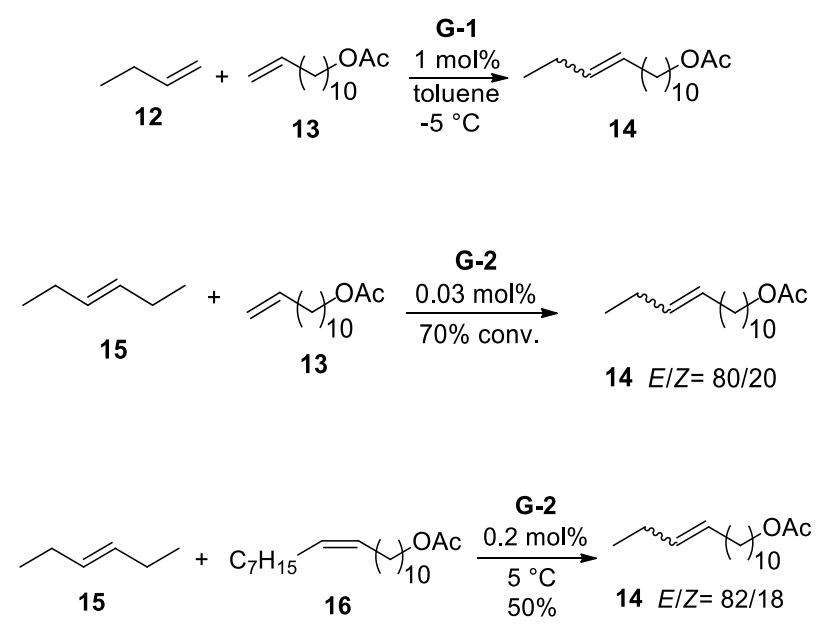

The synthesis of the codling moth (Cydia pomonella) pheromone (20) is noteworthy since the conjugated $E, E$ double bond system of the pheromone was constructed using $\mathbf{G - 1}$ catalyzed olefin metathesis reaction (Scheme 8) ${ }^{38}$ Reaction of 2,4-hexadiene (18) with the chloro olefin 17 provided the desired $E, E$ dienyl intermediate $\mathbf{1 9}$ which was then converted to the pheromone $\mathbf{2 0}$. Although the yield of the metathesis reaction is low (11\%), this reaction is highly relevant as it 
demonstrates the applicability of metathesis reactions in the synthesis of conjugated double bond systems. $^{44-47}$

Scheme 8. Synthesis of pheromone of Cydia pomonella (20)

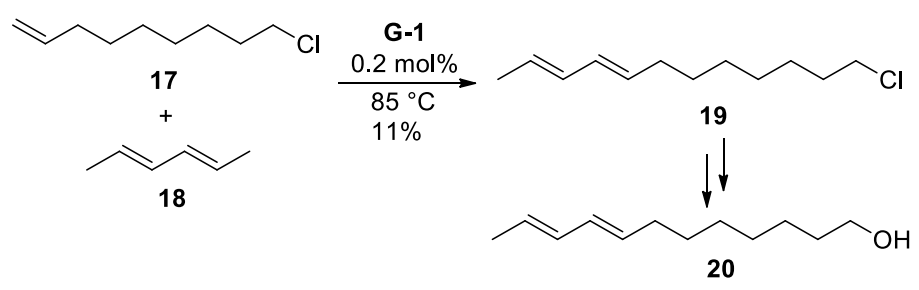

The use of non-edible vegetable oil derivatives, as renewable feedstock from tobacco (Nicotiana tabacum), were also investigated as starting materials for the synthesis of semiochemicals using the Grubbs catalyst, G-2. ${ }^{48}$ The cross-metathesis of methyl esters, $\mathbf{2 1}$ and $\mathbf{2 2}$, resulted in the formation of 6-pentadecene (23), an alarm pheromone component of the acarid mite (Scheme 9). Unfortunately, the 5\% yield of desired product, $\mathbf{2 3}$, is quite low.

Scheme 9. Cross-metathesis of $\mathbf{2 1}$ and $\mathbf{2 2}$ provided the pheromone of acarid mite (23)

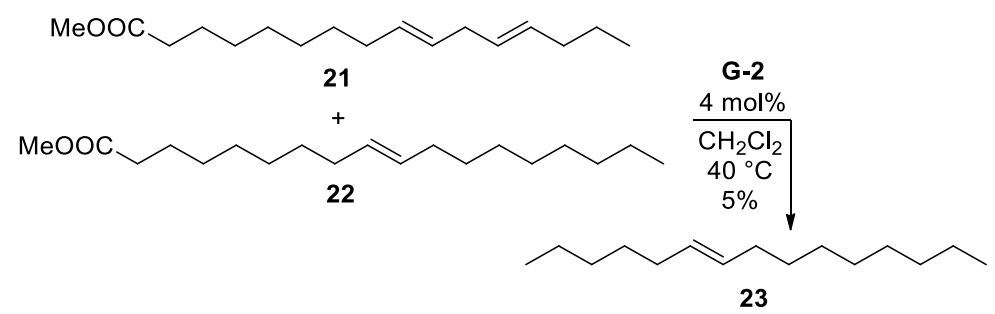

Cross-metathesis of chiral compounds is a very effective tool for introducing chirality into organic molecules and has great relevance to the synthesis of enantiomerically pure, chiral pheromones. For example, an enantiodivergent synthesis of both enantiomers of disparlure, the gypsy moth (Porthetria dispar L.) pheromone, has been reported. $(+)$-Disparlure [(+)-27] was prepared from the chiral intermediate, 26, which was prepared via a $\mathbf{C M}$ reaction using Grubbs 
catalyst, G-2 (Scheme 10). ${ }^{49}$ Similarly, the corresponding enantiomer of the pheromone, (-)-27, was prepared from intermediate 29.

Scheme 10. Enantiodivergent synthesis of both enantiomers of disparlure (27)

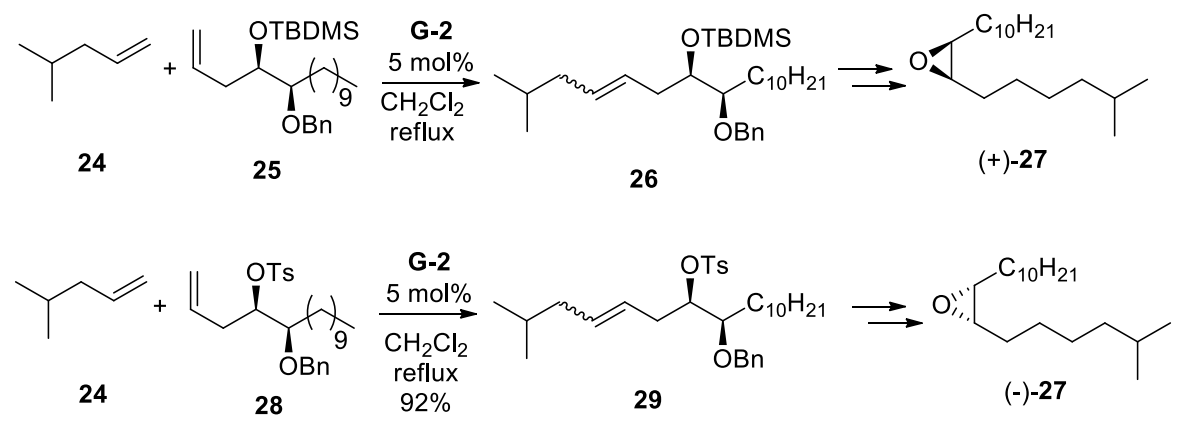

A second, total synthesis of (+)-disparlure and its $E$-isomer using asymmetric catalysis was reported by Kim who employed commercially available D-proline as a chiral catalyst for the synthesis of $\mathbf{2 5}$ (Scheme 11). ${ }^{50}$

Scheme 11. Synthesis of pheromone (+)-27 from optically active amino alcohol (25)

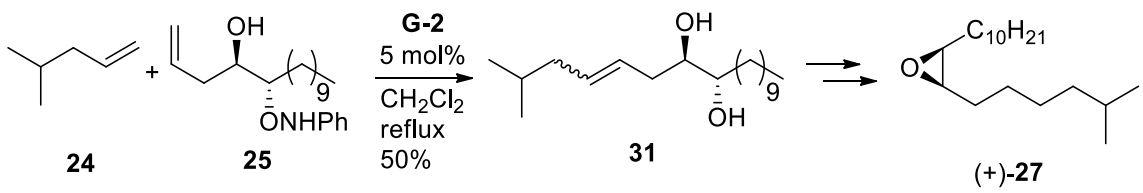

In another example, the (+)-exo and the (-)-endo stereoisomers of brevicomin (35), a pheromone of numerous species of the Dendroctonus family, were synthesized from commercially available starting materials via $\mathbf{C M}$ (Scheme 12). ${ }^{51}$

Scheme 12. Synthesis of the exo and endo isomers of brevicomin (35) 


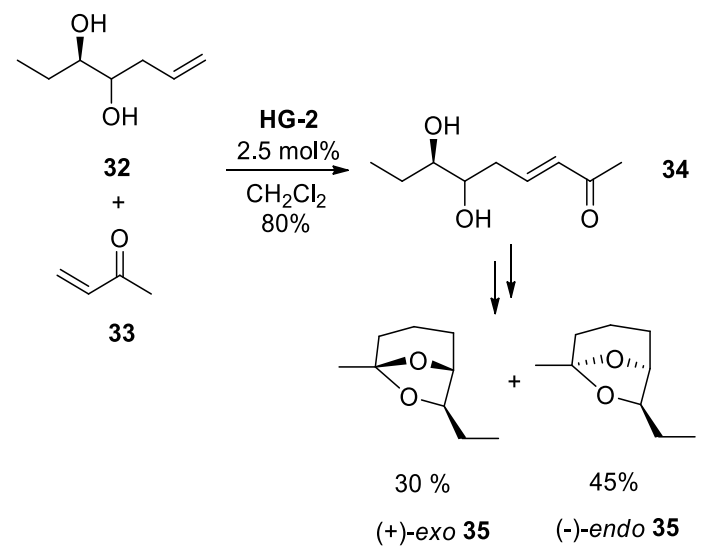

The pharaoh ant (Monomorium pharaonis) trail pheromone (+)-faranal (40) and Lasius meridionalis ant pheromone (-)-lasiol (39) have been synthesized using $\mathbf{C M}$ reactions. The synthetic route to 39 involved six steps. The key metathesis reaction provided the desired enone, 38, in a high yield of $83 \%$. (+)-Faranal was also prepared from intermediate $\mathbf{3 8}$, in a total of nine steps (Scheme 13). ${ }^{52}$

Scheme 13. Synthesis of pharaoh ant (Monomorium pharaonis) pheromones (39 and 40)

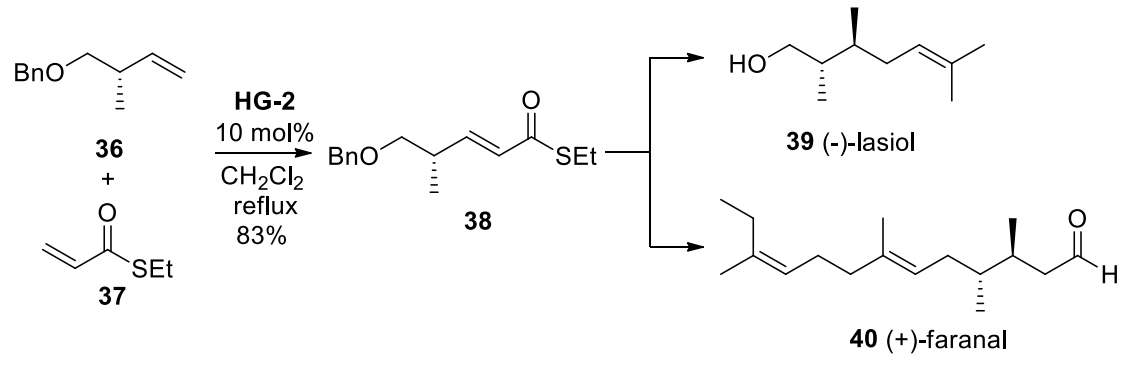

The olefin-containing aldehyde $\mathbf{4 4}$ is the sex pheromone of some species from the Trogoderma genus. The key step in the total synthesis was a cross-metathesis reaction of alkenes $\mathbf{4 1}$ and $\mathbf{4 2}$ that provided intermediate $\mathbf{4 3}$ in moderate yield of 56\% (Scheme 14). Higher stereoselectivity was obtained using the less reactive catalyst G-1. Moreover, application of G-2 led to a high degree of undesired double bond migration resulting in a mixture of olefins as the reaction products (Scheme 14). ${ }^{53}$ 
Scheme 14. Synthesis of pheromone 44, the sex pheromone of species from the Trogoderma genus

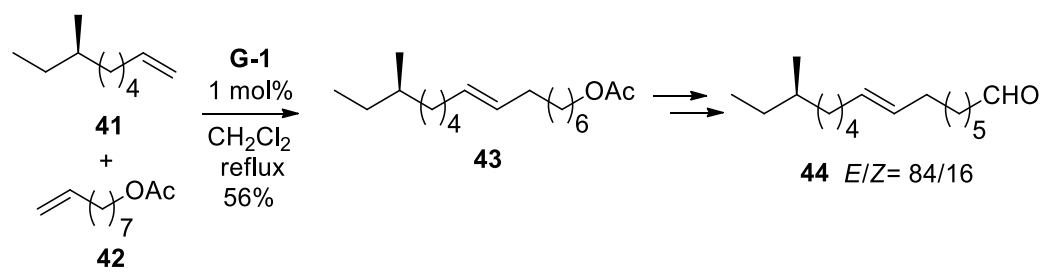

Cross-metathesis was used to prepare the stereoisomers of female-produced, sex pheromone of Lyclene dharma dharma moth, along with the stereoisomers of selected derivatives (Scheme 15). ${ }^{54}$

Scheme 15. Synthesis of moth (Lyclene dharma dharma) pheromone stereoisomers

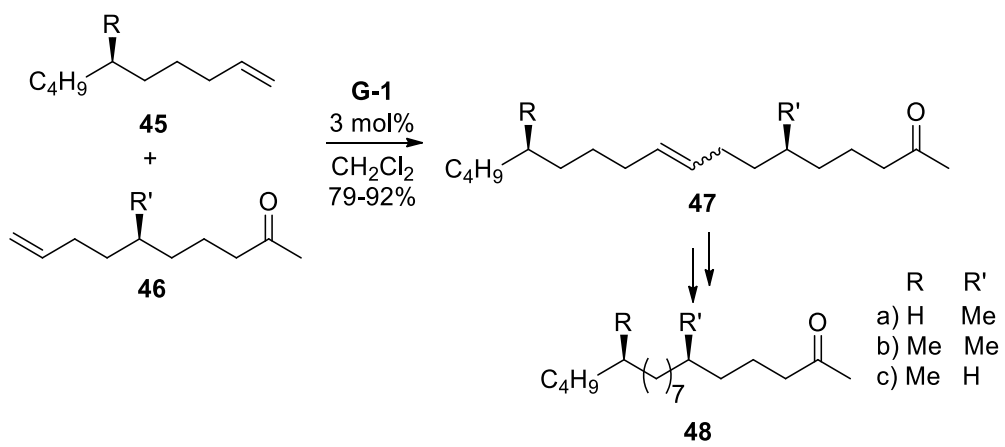

Cross-coupling reactions using Grubbs catalyst systems were used to produce four isomers of (3R,13R,1'S)-1'-ethyl-2'-methylpropyl-3,13-dimethylpentadecanoate (52) which are pheromone components from the Paulownia bagworm (Clania variegata) (Scheme 16). ${ }^{24}$ Biological testing of each stereoisomer indicated that the $\left(3 R, 13 R, 1^{\prime} S\right)$-isomer, $\mathbf{5 2}$, is bioactive one (Scheme 16). ${ }^{25}$

Scheme 16. Synthesis of pheromone of Clania variegata (52) 


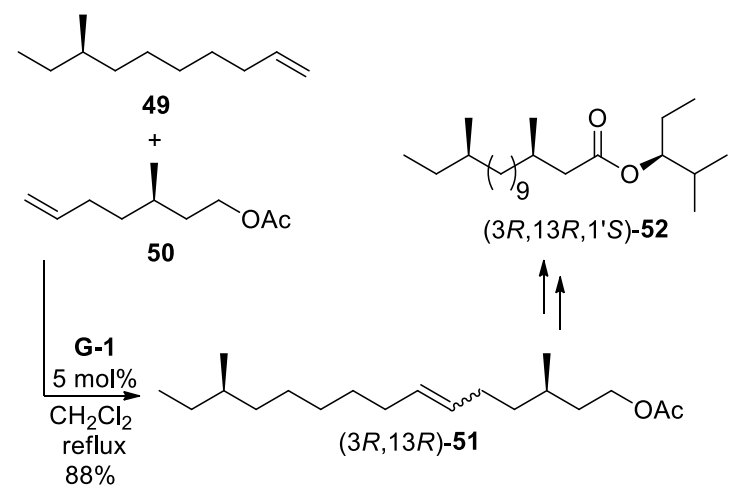

The total synthesis of (-)-6-acetoxy-5-hexadecanolide $[(5 R, 6 S)-56]$, the pheromone of the mosquito Culex pipiens fatigans and Culex quinquefasciatus, was carried out by one-pot ringclosing and cross-metathesis ( $\mathbf{R C M} / \mathbf{C M}$ ) reactions (Scheme 17), ${ }^{57,58}$ based on the general method of Piva et al. ${ }^{59,60}$

Scheme 17. Synthesis of 56, the pheromone of Culex pipiens fatigans and Culex quinquefasciatus<smiles>C=CCC(=O)OC(C=C)C(C=C)Cc1ccccc1</smiles>

53

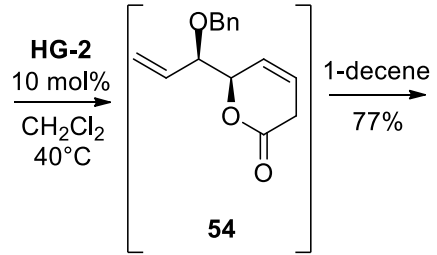<smiles>C=CC=CC(OC(C)C)C(C=CCCC)OC(=O)c1ccccc1</smiles>

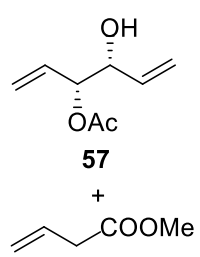

1.2 equiv. 58
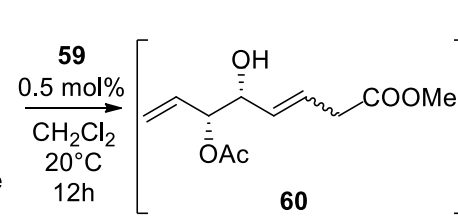

60
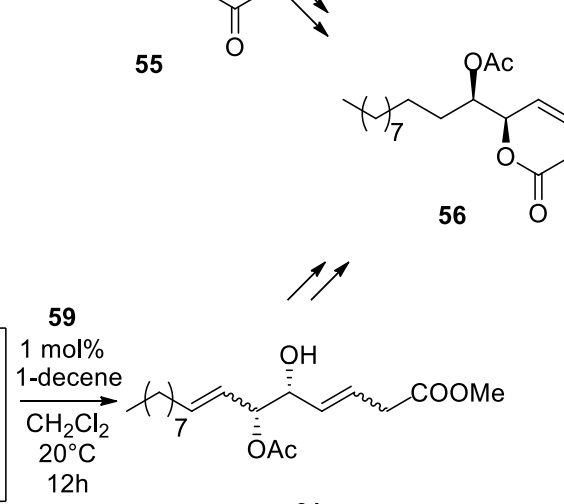

61

The total synthesis of the female sex pheromone of Macrodiprion nemoralis (65) via $\mathbf{C M}$ using a Hoveyda-Grubbs second generation catalyst was reported by Loh et al. (Scheme 18). ${ }^{61}$

Scheme 18. Synthesis of the sex pheromone of Macrodiprion nemoralis (65) 


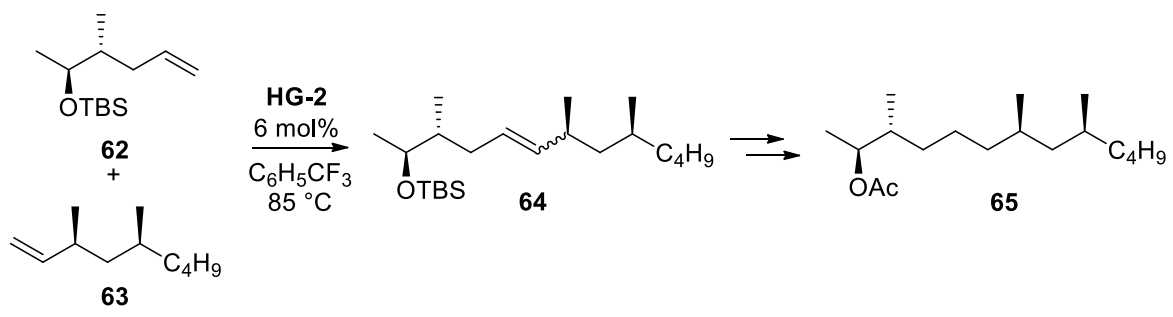

The triene haminol-A (69), an active substance towards nematode Caenorhabditis elegans, was synthesized using G-2 catalyzed olefin metathesis. The key $\mathbf{C M}$ step involved the alpha-alkene 66, with its masked alkene, and crotonaldehyde (67). The reaction provided key intermediate 68 that was eventually converted to the final product 69 after unmasking of the alkene via elimination of an acyloxysulfone (Scheme 19). ${ }^{62}$

Scheme 19. Synthesis of haminol-A (69)

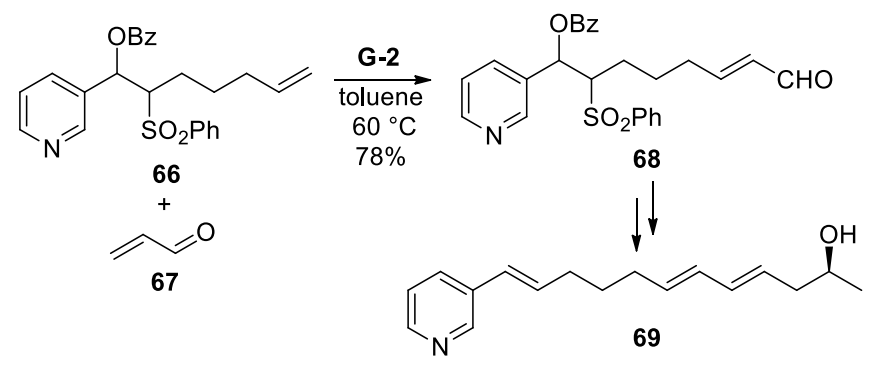

The Caenorhabditis elegans secretes ascarosides that can act as semiochemicals. More than 20 ascarosides were synthesized as potential dauer pheromones that are important to nematode development (Scheme 20). ${ }^{63}$

Scheme 20. Synthesis of dauer pheromones of Caenorhabditis elegans via CM

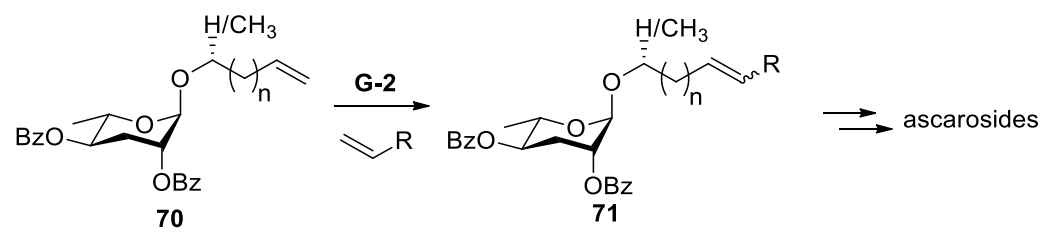


The enantiospecific total synthesis of $(R)$-10-methyl-2-tridecanone female sex pheromone of Southern corn rootworm (Diabrotica undecimpunctata howardi) (75) has been reported. The nine-step synthesis features a cross-metathesis as the key transformation. Reaction of $(R)-6$ methyl-1-nonene (72) and 5-hexen-2-one (73) in the presence of Grubbs catalyst G-1 provided the key intermediate 74 in moderate yield of $73 \%$ (Scheme 21). ${ }^{64}$

Scheme 21. Synthesis of pheromone of Diabrotica undecimpunctata howardi (75)

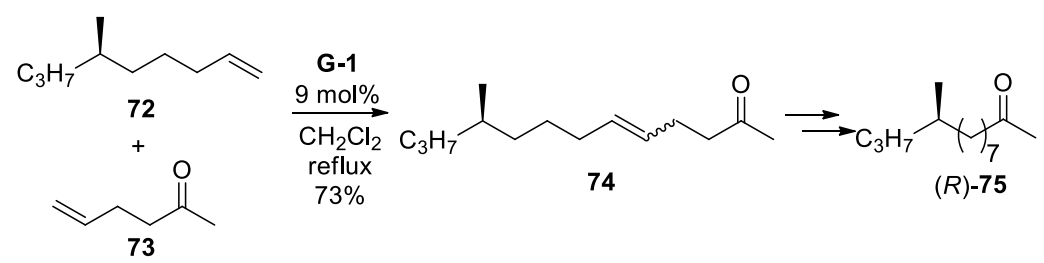

The male pheromone of the red-necked longhorn beetle (Aromia bungi), 78, was prepared via a ruthenium catalyzed CM reaction of optically pure $(3 S, 4 R)-\mathbf{7 6}$, and but-2-enal (77) (Scheme 22). The requisite alkenyl epoxide $(3 S, 4 R)$-76 was synthesized from $Z$-penten-2-ol in three steps that employed a Sharpless oxidation reaction and a catalytic amount of D-(-)-diethyl tartarate. Both optically active enantiomers of the pheromone were synthesized in high $e e$. The enantiomer of the target pheromone, $(6 R, 7 S)-78$, was prepared by using L-(-)-diethyl tartarate, in Sharpless oxidation..$^{65}$

Scheme 22. Synthesis of 78, pheromone of Aromia bungi

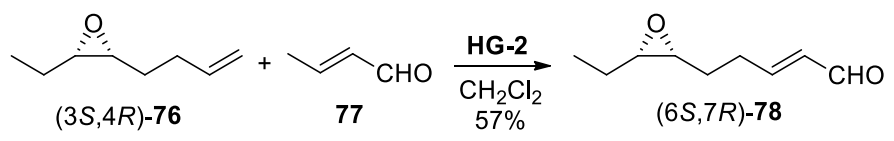

A cross-metathesis reaction was a key transformation in the total synthesis of a racemate mixture of pheromone 82, a ketal isolated from fruit flies Dacus oleae and Bactrocera oleae (Scheme 23). 
Intermediate 81 was obtained in $46 \%$ in the $\mathbf{C M}$ involving commercially available starting materials 79 and 80 and catalyst HG-2. ${ }^{65}$

Scheme 23. Synthesis of the pheromone of Dacus oleae and Bactrocera oleae (82)

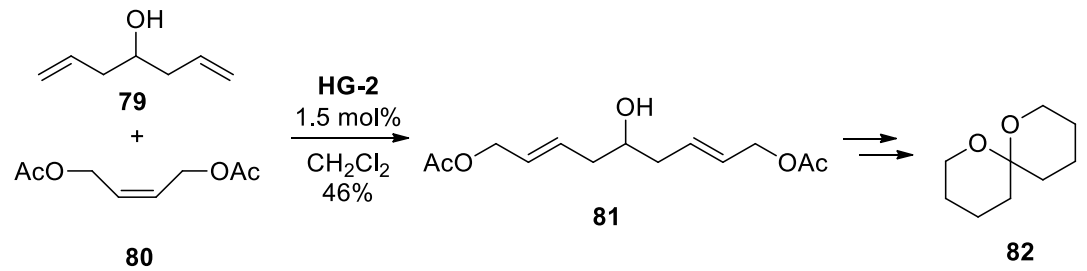

\section{$Z$-selective Ru-alkylidene catalyzed cross-metathesis reactions}

The Grubbs first generation (G-1) and second generation (G-2) catalysts showed predominantly $E$ selectivity (80\%); ${ }^{66}$ however, a high percentage of insect pheromones have $Z$-alkene moieties. Consequently, cross-metathesis reactions were not the transformation of choice. Such compounds were mostly synthesized by Wittig reaction with stabilizer ylides or by the reduction of alkynes with hydroboranes or Lindlar catalyst. ${ }^{19}$ Unfortunately, borane reduction suffer a similar liability as Wittig reactions, namely the stoichiometric amount of side products from the reagents, while the Lindlar catalysts contain toxic lead-salts. A greener, synthetic approach would be preferable.

Early examples of synthetic routes to target compounds containing $Z$-alkenes using ruthenium catalyzed $\mathbf{C M}$ required additional modification of intermediate $E$-alkenes. For example, metathesis of $\mathbf{8 3}$ and $\mathbf{8 4}$ produced the $E$-vinyl borane (85) as the major product, which was subsequently transformed to the desired $Z$-vinyl bromide intermediate as a mixture of stereoisomers (Scheme 24). ${ }^{67}$ 
Scheme 24. Synthesis of $Z$-alkenes via $E$-vinyl-boron intermediate

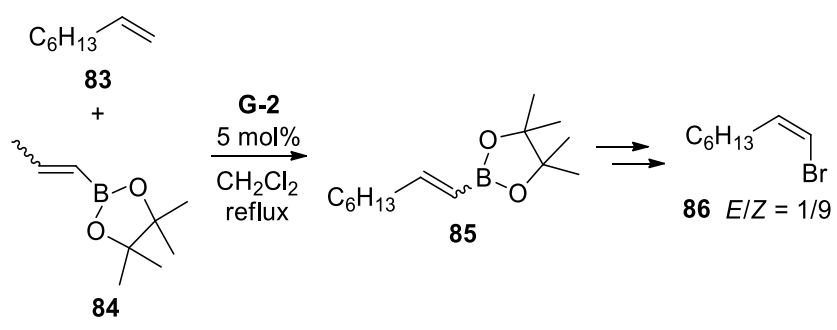

The selectivity limitation of the early ruthenium catalysts has been addressed and Zselective Ru catalysts have been reported (GZ-1) which enables the convenient synthesis of Zalkenes with reasonable yields and stereoselectivity. ${ }^{68}$ Some of these catalysts are already commercially available (Scheme 25).

Scheme 25. Z-selective catalysts (Mes = 2,4,6-trimethylbenzene, DIPP = 2,6-di-isopropylbenzene)

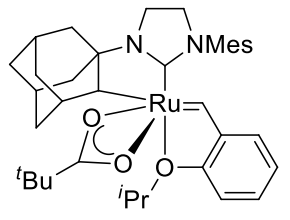

GZ-1

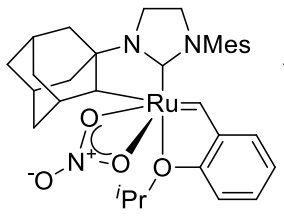

GZ-2

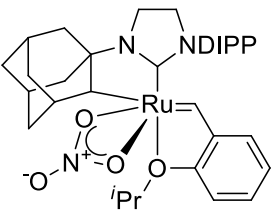

GZ-3

The utility of these improved catalysts was demonstrated in the total synthesis of pheromone $\mathbf{8 8}$ (Scheme 26). The synthesis is one of the first industrially relevant examples of the use of a C-H activated Grubbs catalyst GZ-2, ${ }^{69}$ is a highly efficient ruthenium catalyst $(\mathrm{TON}=$ ca. 1000$)$ that can be employed for the synthesis of $Z$-olefin containing pheromones and biomaterials using low catalyst loading (e.g., $0.5 \mathrm{~mol} \%$ ).

Scheme 26. Synthesis of pheromone $\mathbf{8 8}$

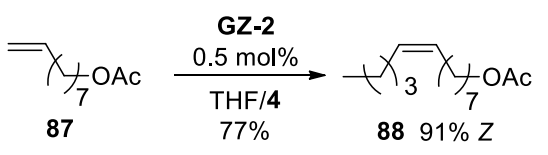


The use of catalyst, GZ-2, produced the $Z$-alkenyl pheromone $\mathbf{8 8}$ in good yield (77\%) and high $Z$ to $E$ selectivity $(91 \% Z)$ in only one step, instead of six steps as previously reported in the literature. ${ }^{70}$ One year after the publication, the synthesis of seven additional pheromones were reported using the same catalyst. ${ }^{71,72}$ The $\mathbf{C M}$ reactions proceeded with good yields (76\%-88\%) and stereoselectivity $(76-86 \%$ Z) (Scheme 27).

Scheme 27. Synthesis of seven $Z$-monoene pheromones

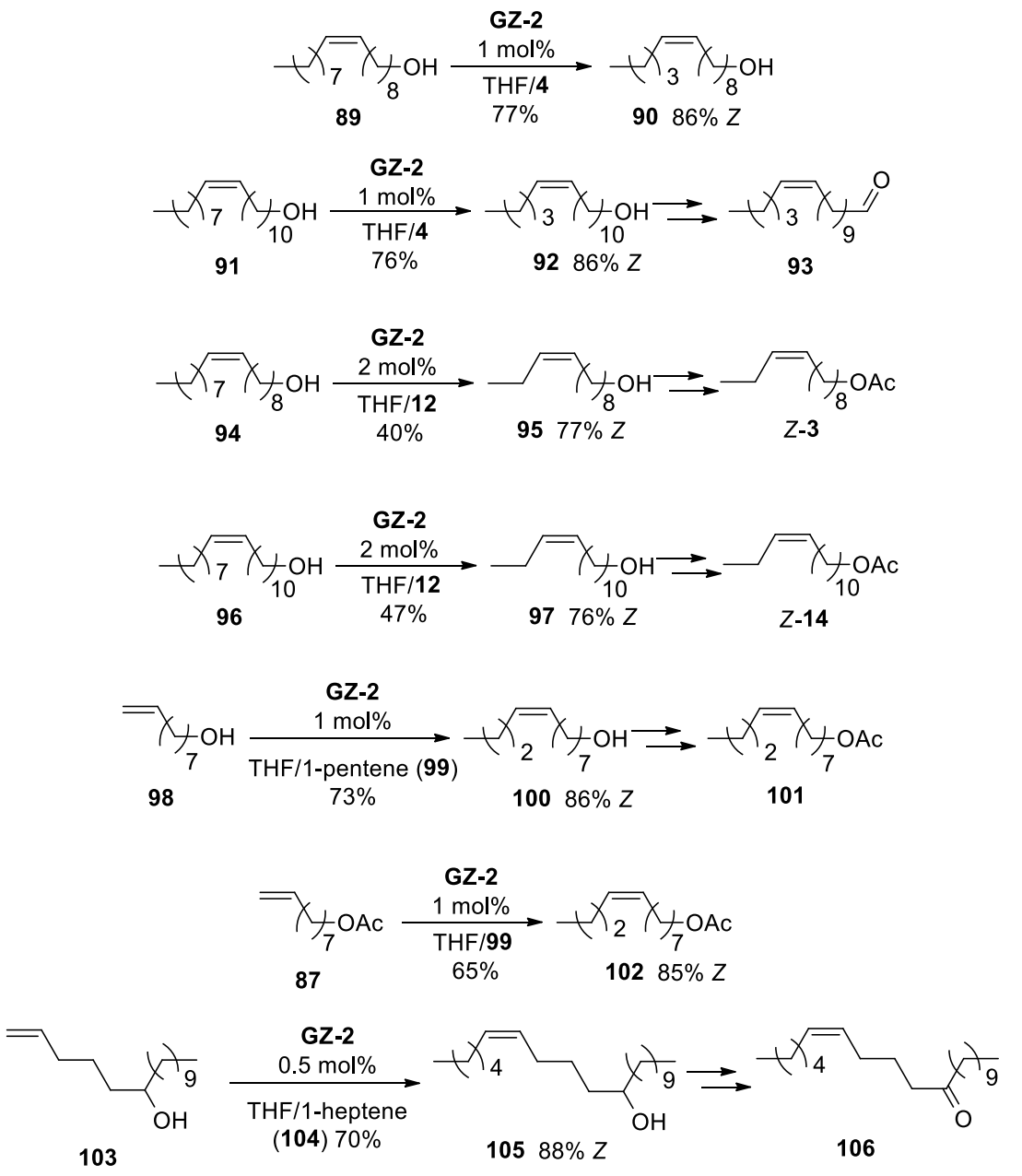

The GZ-2 catalyst was also employed to prepare racemic disparlure (27) in which the key metathesis reaction gave predominately the $Z$-alkenyl intermediate 109 in moderate yield (64\%) and good selectivity $(84 \% \mathrm{Z})$. (Scheme 28$)$. 
Scheme 28. Synthesis of disparlure (27)

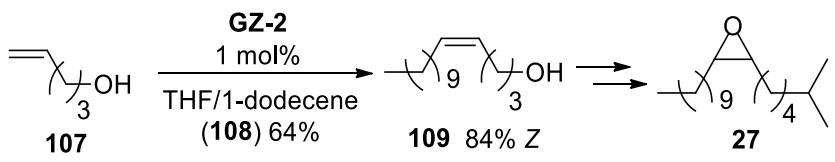

An advantage of the GZ-2 catalyst is that it does not tend to react with $E$-alkenes. The selectivity provides a new route for the preparation of unconjugated $E, Z$ dienes. The reaction between $E$ 1,4-hexadiene (110) and 94 resulted in the exclusive formation of unconjugated 111, which then subsequently could be acylated to 112, the pheromone of olive pyralid moth (Euzophera pinguis). The use of GZ-2 simplified the route to $\mathbf{1 1 2}$ to just 2 steps instead of the formerly reported six steps (Scheme 29). ${ }^{73,74}$

Scheme 29. Synthesis of isolated diene (112), the pheromone of Euzophera pinguis

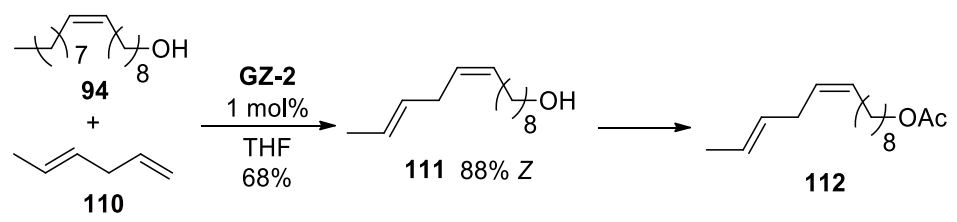

Further catalyst development led to the identification of GZ-3 (see Scheme 25 for structure), ${ }^{75}$ a catalyst that enables the synthesis of conjugated E,Z-dienes. GZ-3 does not react and isomerize $E$-double bonds, making possible the synthesis of $E, Z$ conjugated dienes. For example, dienes 114 and 116 were prepared with high $Z$-selectivity $(>90 \%)$ while retaining the $E$-configurations of the starting materials $\mathbf{1 1 3}$ and 115, albeit in low to moderate yields (Scheme 30).

Scheme 30. Synthesis of conjugated dienes with GZ-3 


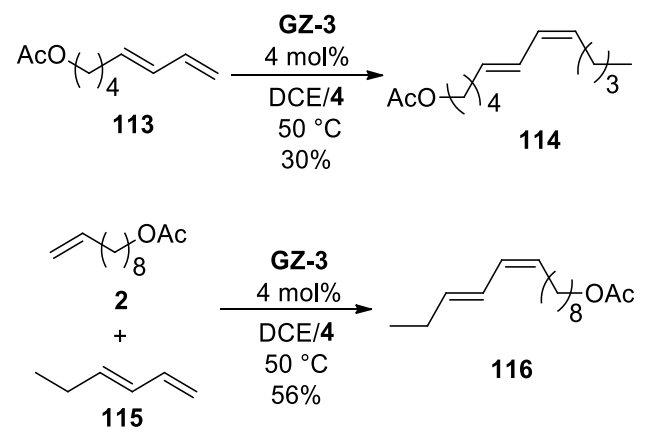

\section{Application of ring-opening cross-metathesis (ROCM)}

Ring-opening cross-metathesis (ROCM) provides a convenient and unique method to produce $Z$-alkenes. The use of molybdenum catalysts has been extensively studied in this area of olefin metathesis. The previously mentioned omnivorous leafroller pheromone (14) was successfully prepared using ROCM (Scheme 31$){ }^{76}$

Scheme 31. Synthesis of omnivorous leafroller pheromone 14 via ROCM

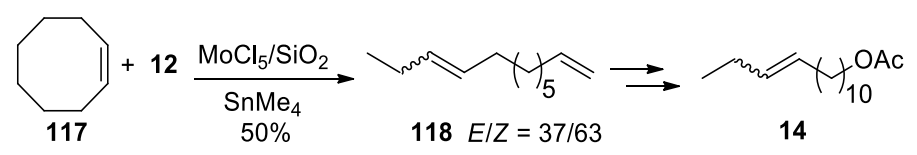

In another example, Lepidoptera sex pheromones 122 and $\mathbf{8}$ were generated using the ROCM reaction. The key step produced the expected $Z$-triene, 121, with excellent $Z$-selectivity (98.8\%). The $Z$-triene was subsequently converted to the pheromones 122 and $\mathbf{8}$ (Scheme 32). ${ }^{77}$

Scheme 32. Synthesis of Lepidoptera pheromones (122 and $\mathbf{8}$ )

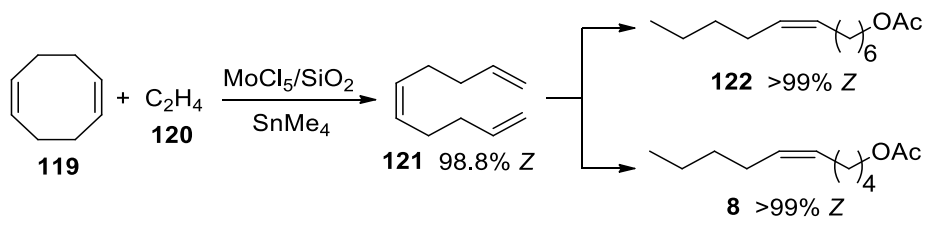


The natural occurring pheromone, 123, of the Varied carpet beetle (Anthrenus verbasci) is a mixture of stereoisomers $(E / Z=15 / 85)$. The earlier reported preparations of the pheromone employed Witting reactions that provided mixtures of $E / Z$ isomers with contrasting selectivities $\left(E / Z=25 / 75^{78}\right.$ and $\left.E / Z=82 / 18\right) .{ }^{79}$ ROCM (Scheme 33) made it possible to synthesize the exact $E / Z$ ratio of isomers found in the naturally occurring pheromone by changing the metathesis conditions and preparing $E / Z=1 / 99$ and $E / Z=79 / 21$ mixtures then mixing them to get the desired ratio. ${ }^{80}$

Scheme 33. Synthesis of Anthrenus verbasci pheromone 123

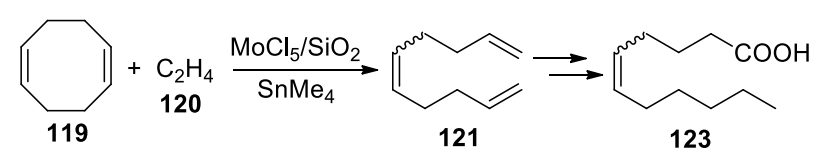

The brown algae pheromones, $\mathbf{1 2 5}$ and $\mathbf{1 2 6}$ were synthesized with moderate regioselectivity (4:1 ratio of 125:126) and stereoselectivity ( $E / Z$ ratios of $9 / 1$ and $1 / 2)($ Scheme 34$) .{ }^{81}$

Scheme 34. Synthesis of brown algae pheromones (125 and 126) with 1-octene

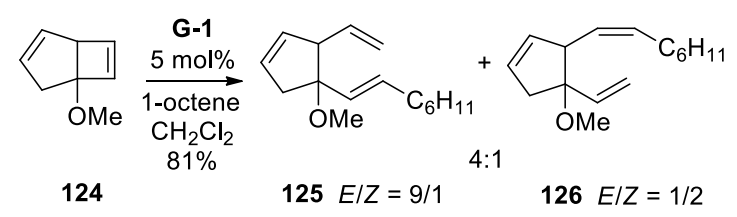

Similar to the above mentioned examples, G-1 catalyzed routes to produce Glossyplur (130) the pink bollworm (Pectinophora gossypiella) pheromone as a mixture of $E / Z$ isomers, as can be seen in Scheme 35. ${ }^{38}$

Scheme 35. Synthesis of pheromone of Pectinophora gossypiella (130) 


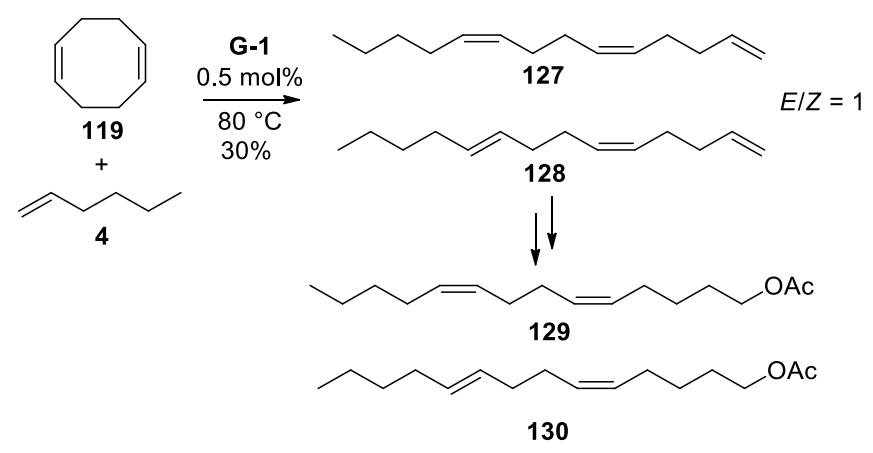

The (+)-endo enantiomer of the already mentioned brevicomin (35) was formed with excellent enantioselectivity by applying an asymmetric ring-opening cross-metathesis (AROCM) with the Z-selective catalyst GZ-2 (Scheme 36). ${ }^{82}$

Scheme 36. Synthesis of brevicomin (35)

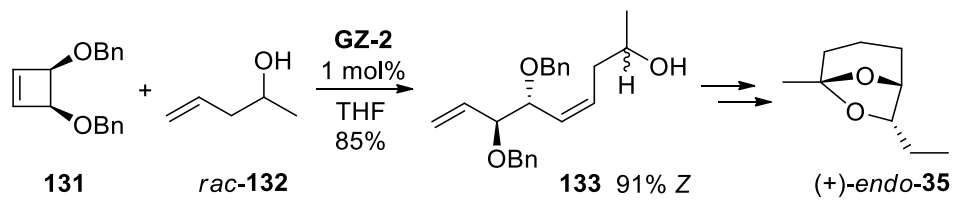




\section{Ring-closing metathesis (RCM) examples}

Ring-closing metathesis ( $\mathbf{R C M}$ ) reactions are also proven to be useful in pheromone synthesis. Due to unfavourable enthalpic and entropic effects, the formation of medium- and large-sized rings are a more complex synthetic task in general, compared to small ring closures. However, RCM is amongst the most straightforward entries into large ring systems and favorable compared to all current alternatives. RCM has also been used for the construction of bridged systems that are so ubiquitous in natural products. Two, early examples of the use of Ru catalyzed RCM reactions to produce macrocycles are shown in Scheme 37. In the first example, the aggregation pheromone of the flat grain beetle (Cryptoletes pusillus) $\mathbf{1 3 6}$ was generated in moderate yield (71\%) from the diene 134 using the conjugated Ru catalyst, $\mathbf{1 3 5} .{ }^{83,84}$ In the second example, macrocycle 138 was produced from 137 using G-1 in good yield (80\%).

Scheme 37. Preparation of pheromone macrocycles 136 and 138

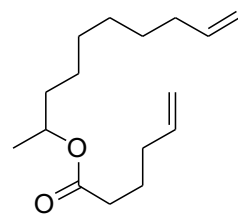

134

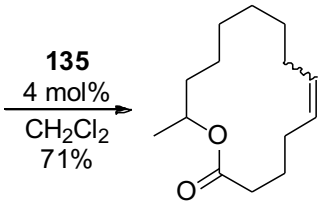

136

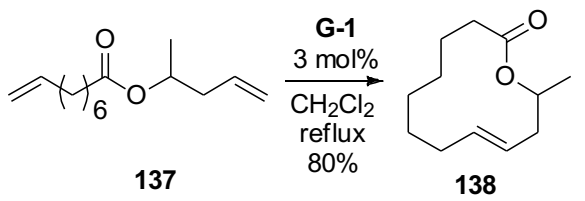

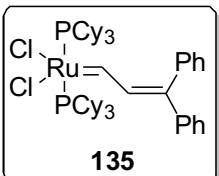

135 the aggregation pheromone of the flat grain beetle (Cryptoletes pusillus) 136 was generated in 
semiochemical, 2-methyl-11-dodecanolidine that is secreted by mantellid frogs (Gephyromantis moseri) ${ }^{85}$

Scheme 38. Preparation of pheromone-like macrocyclic esters (141) by olefin metathesis followed by hydrogenation

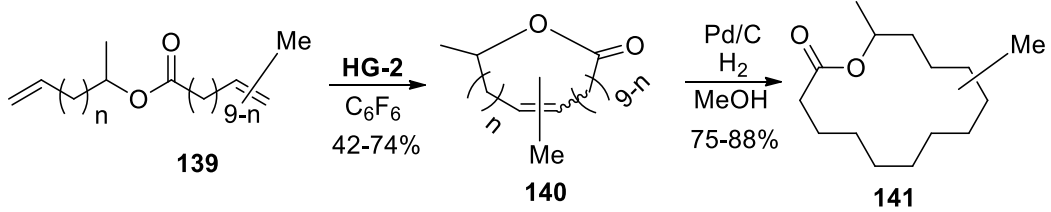

RCM has been used in the preparation of chiral compounds such as brevicomin (35). The synthesis of brevicomin via CM and AROCM reactions were highlighted earlier in this review. In this example, the stereoselective construction of the 6,8-dioxabicyclo[3.2.1]-octane skeleton of brevicomin was produced by the desymmetrization of triene substrate 142 via ring-closing metathesis (Scheme 39). ${ }^{86}$

Scheme 39. Synthesis of brevicomin (35) via RCM

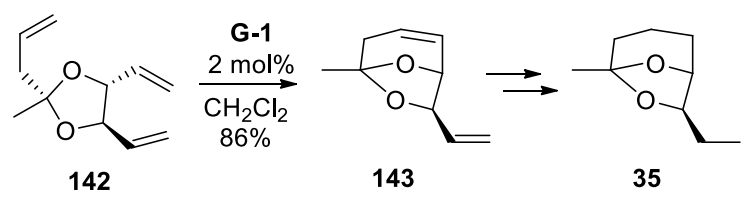

The synthesis of (-)-frontalin, the pheromone of the southern bark beetle (Dendroctonus frontalis), was also achieved in only four steps and high yield using RCM as a key step (Scheme 40). Cyclization of the diene precursor 144 using ruthenium-catalyzed $\mathbf{G}-\mathbf{1}$ gave the tricyclic ketal 145 that was reduced to give (-)-frontalin. This was the first report of the formation of small ring bridged oxygen heterocycles using $\mathbf{R C M} .^{87}$

Scheme 40. Synthesis of (-)-frontalin, pheromone of Dendroctonus frontalis (146) 


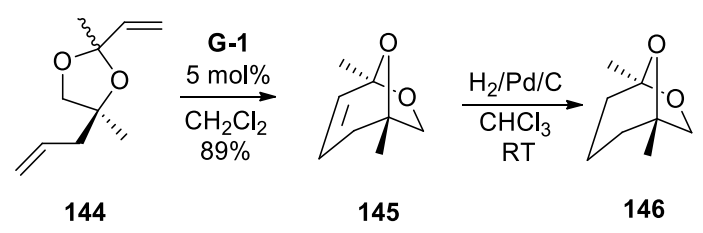

The enantioselective, total synthesis of the oriental hornet (Vespa orientals) pheromone, $\mathbf{1 4 9}$, was completed by using G-1 (Scheme 41). ${ }^{88}$

Scheme 41. Synthesis of pheromone of Vespa orientals (149)

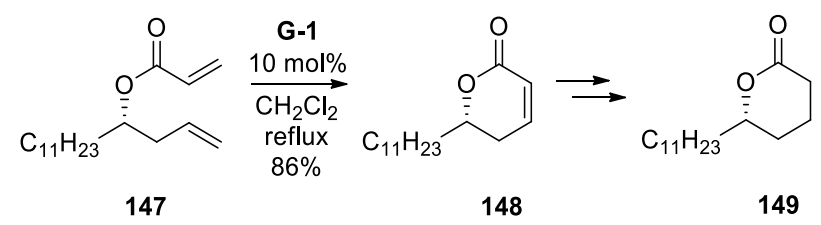

Intermediate (147) was synthesized later using L-proline as a chiral inductor and closed in the same RCM fashion to produce 148. ${ }^{89}$ The synthesis of fire ant (Solenopsis invicta) pheromone (152) employed a similar RCM-reduction protocol (Scheme 42) ${ }^{89}$

Scheme 42. Synthesis of pheromone of Solenopsis invicta (152)

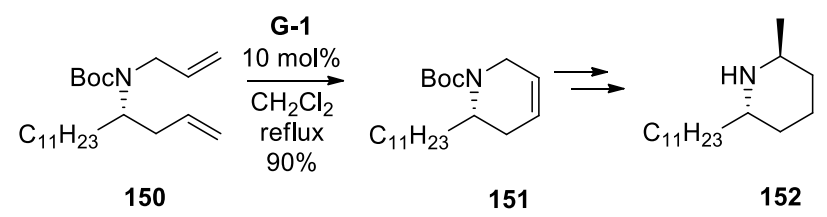

Olefin metathesis reaction can also be used for the total synthesis of biologically active spiro compounds including the semiochemical of the (Andrena) bee genus, 155. The construction of the spiroketal 154 via ruthenium catalyzed ring-closing reaction of 153 was carried out with retention of the stereochemical integrity (Scheme 43). The RCM approach demonstrates an alternative method toward the efficient synthesis of spiroketals. ${ }^{90,91}$ 
Scheme 43. Synthesis of pheromone of Andrena bee genus (155)

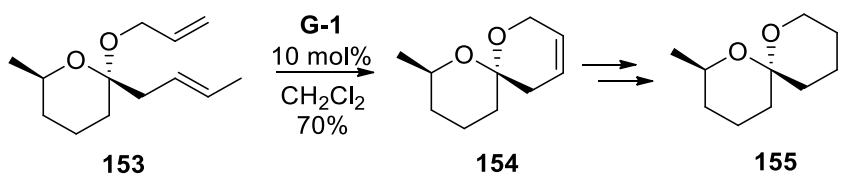

The sex pheromone, $( \pm)$-Periplanon C (158), of the American cockroach (Periplaneta Americana) was synthesized in eleven steps, including a G-1 catalyzed RCM (Scheme 44). RCM provided 157 which was followed by ring enlargement by $\beta$-fragmentation in a new sequence for stereoselective synthesis of medium-sized $(Z)$-cycloalkenes. ${ }^{92}$

Scheme 44. Synthesis of American cockroach (Periplaneta Americana) sex pheromone $( \pm)$ Periplanon C (158)

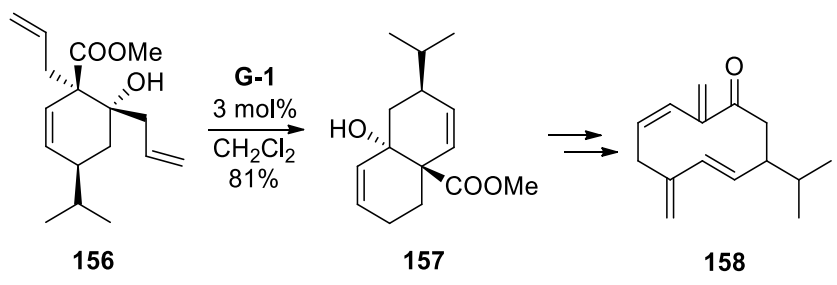

The attractant pheromone, 56, of mosquito (Culex pipiens fatigans) was prepared from chiral building blocks ${ }^{93}$ and from chiral additives ${ }^{94}$ (Scheme 45). In both cases the key step of the pheromone synthesis is the ruthenium catalyzed formation of the six-membered ring from compound 159 and 161 respectively.

Scheme 45. Synthesis of pheromone of Culex pipiens fatigans (56) by ring-closing metathesis 


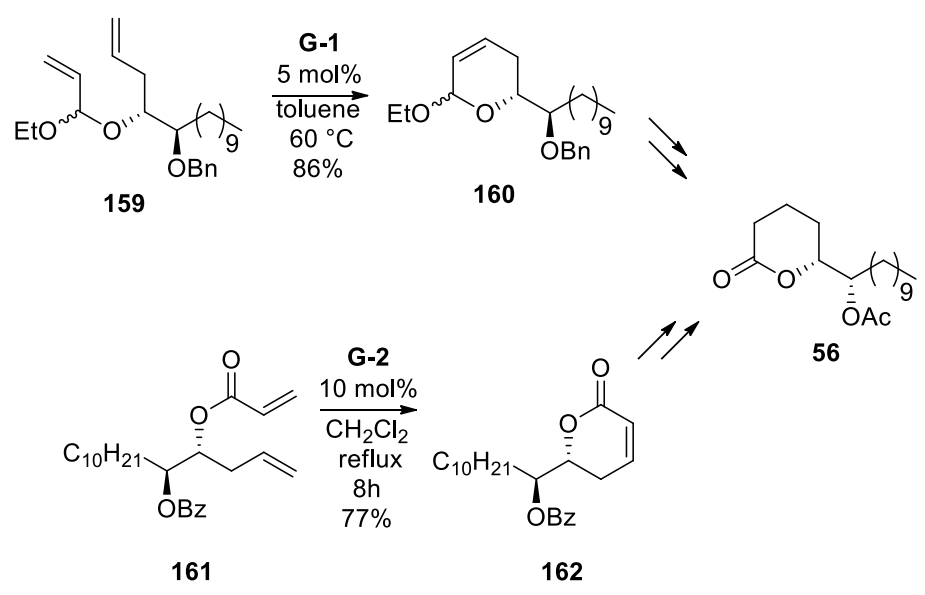

The enantioselective synthesis of $\mathbf{1 6 5}$, the sex pheromone of the orange wheat blossom midge (Sitodiplosis mosellana) was reported by Pickett. The $2 S, 7 S$ configuration was revealed to have the highest biological activity (Scheme 46). ${ }^{95}$

Scheme 46. Synthesis of pheromone of Sitodiplosis mosellana (165)

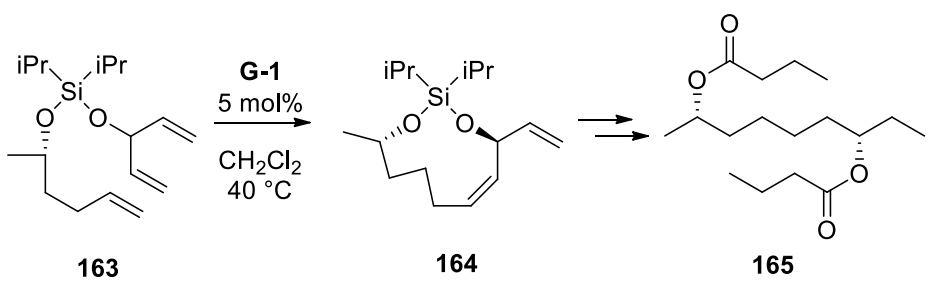

The two pheromones of the giant white butterfly (Idea leuconoe) pheromone (168) were synthesized by ruthenium (G-2) catalyzed RCM of $\mathbf{1 6 6}$ (Scheme 47) ${ }^{96}$

Scheme 47. Synthesis of pheromones of Idea leuconoe (168)

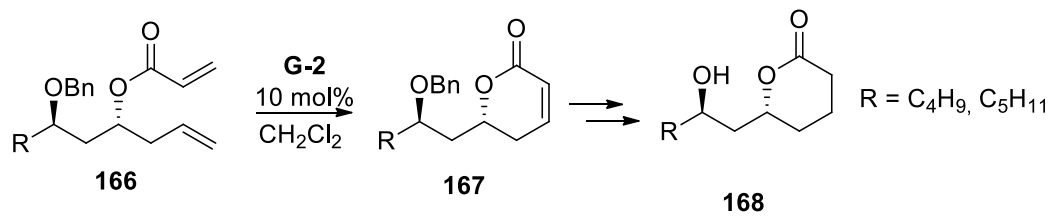


G-2 catalyzed RCM was used to construct the trieneyl pheromones of the small and large cabbage butterflies' (Pieris rapae and P. brassicae). The mixtures of three different stereoisomers $[(E, E, E)-\mathbf{1 7 0},(Z, E, E)-\mathbf{1 7 0},(E, Z, E)-\mathbf{1 7 0}]$ were prepared as shown in Scheme $48 .{ }^{97}$

Scheme 48. Synthesis of macrocyclic pheromones of Pieris rapae and P. brassicae $(\mathbf{1 7 0}, \mathbf{1 7 3})$
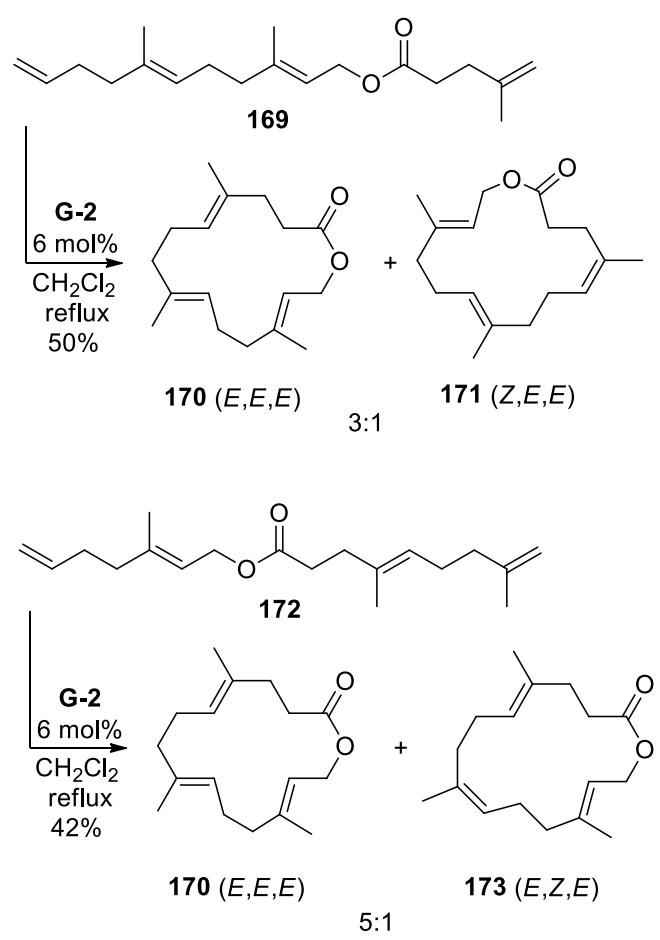

The semiochemical, 176, of the sandfly (Lutzomyia longipalpis) was synthesised via a five-step sequence. The ability to conduct the ruthenium catalyzed RCM of 174 on preparative scale made it possible carrying out extensive bioassays of $\mathbf{1 7 6}$ (Scheme 49). ${ }^{98}$

Scheme 49. Synthesis of sandfly's (Lutzomyia longipalpis) pheromone 176

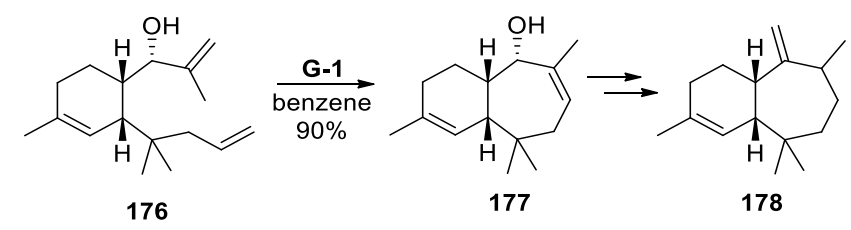


The enantioselective synthesis of the sex pheromone from the longtailed mealybug (Pseudococcus longispinus) was reported by Reddy. The synthesis employed racemic starting materials and involved a Meyer-Schuster-Claisen rearrangement and a RCM reaction using G-2 as the catalyst (Scheme 50). The overall yield of the synthesis was $50 \% .{ }^{99}$

Scheme 50. Synthesis of pheromone of Pseudococcus longispinus, 181

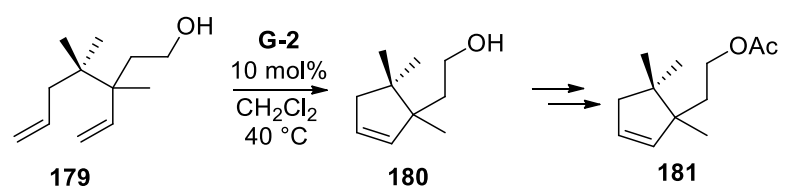

Changing the order of the metathesis and acylation steps significantly improved the overall yield of 181 (from $50 \%$ to $71 \%$ ) (Scheme 51). The starting material 179, which features adjacent quaternary carbons, was generated by a Claisen rearrangement. The acylation of $\mathbf{1 7 9}$ followed by ruthenium catalyzed RCM led to the enantiomerically pure $(S)-181 .{ }^{100}$ Both enantiomers of the pheromone 181 were synthetized by this route. The $(S)-(+)$-enantiomer showed high activity towards male mealybugs while the $(R)$-(-)-enantiomer showed neither attractive nor inhibitory activity.

Scheme 51. Synthesis of pheromone of mealybugs $[(S)$-181]

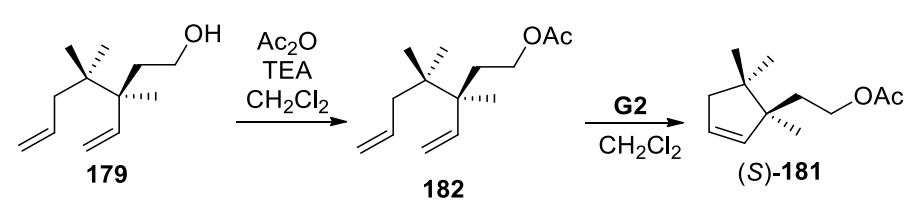

Two alternative ways for the racemic synthesis of the female-produced sex pheromone, $\mathbf{1 8 5}$, of the Pineapple mealybug (Dysmicoccus brevipes) was reported by Tabata. Key steps included an Ireland-Claisen rearrangement or conjugate addition for the preparation of the quaternary carbon 
center and RCM for the construction of the cyclopentene ring. ${ }^{101}$ The authors identified the absolute configuration of the biologically active component as (1S,2S)-185 (Scheme 52). ${ }^{102}$

Scheme 52. Different synthetic routes for pheromone of Dysmicoccus brevipes (185) (PMB = 4Methoxybenzyl)

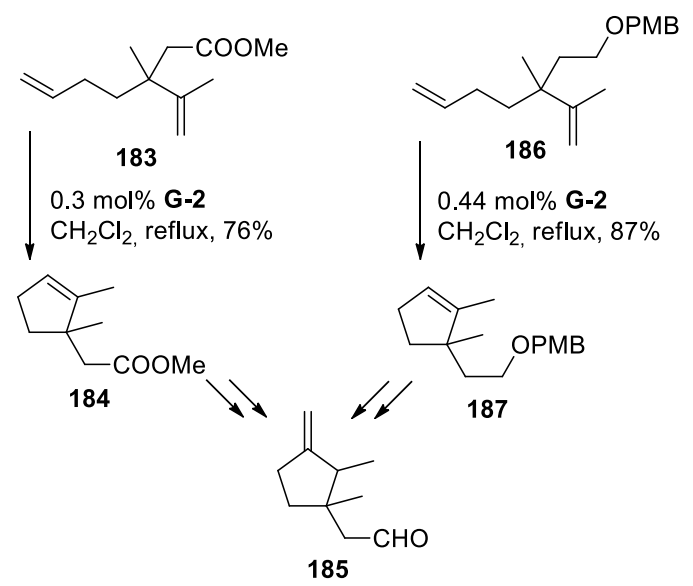

\section{Other methods}

\section{$\operatorname{RCAM}(\mathbf{W}$ and Mo)}

Ring-closing alkyne metathesis (RCAM) is an elegant method to form unsaturated macrocycles. ${ }^{103,104}$ Cucujolides (macrolide lactones) are part of the pheromone mixtures of the cucujid grain beetle. Cucujolide V (194) and cucujolide X (191) compounds were synthesized via tungsten based homogeneous catalysis with high yield at moderate reaction condition (Scheme 53). ${ }^{105}$

Scheme 53. Synthesis of cucujolides, using tungsten metathesis catalyst (189) 


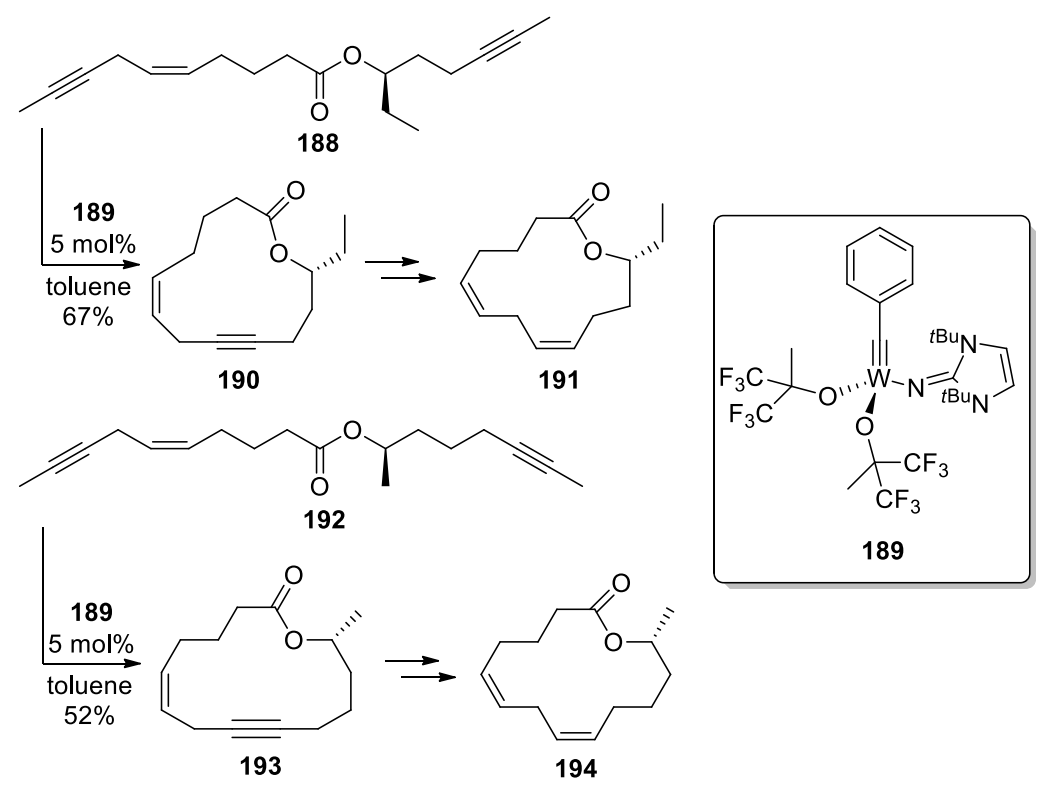

From the same family of compounds, cucujolide XI was synthesized by RCAM using molybdenum catalyst 196 . The highly active organometallic complex, 196, allowed the use of a terminal alkyne with excellent yield. Cucujolide XI was the first macrolide pheromone oxidized at the $\omega-4$ position (Scheme 54). ${ }^{106}$

Scheme 54. Synthesis of cucujolide XI via RCAM using molybdenum metathesis catalyst 196
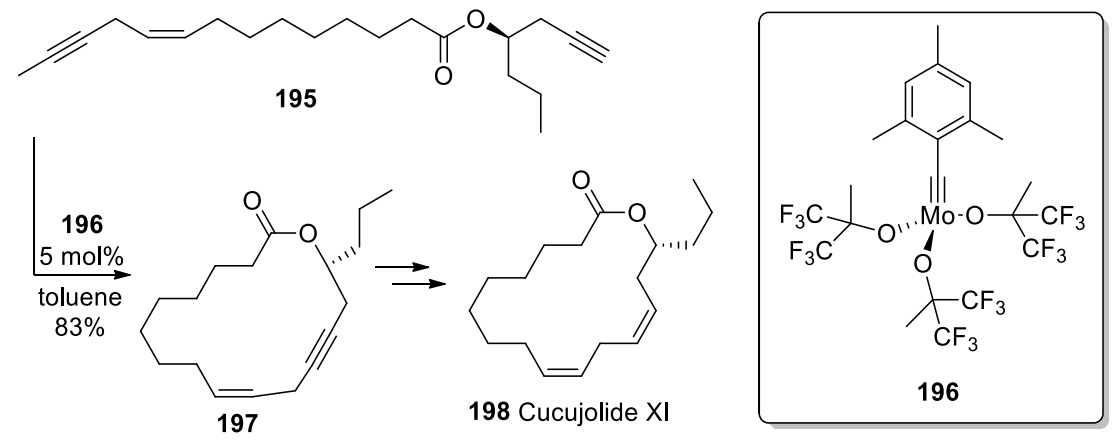

\section{Ru-ENYNE}

The enyne metathesis is a ruthenium-catalyzed bond reorganization of an alkene and an alkyne, resulting in a conjugated 1,3-diene. ${ }^{68,69}$ There are two types. The first type is the cross-enyne 
metathesis (CEM) in which the coupling partners are intermolecular. The second type is an intramolecular process in which the alkene and alkyne are within the same molecule. The reaction is referred to as a ring-closing enyne metathesis (RCEYM). ${ }^{109}$

Grandisol, the primary constituent of the grandlure, is a mixture of four pheromones that comprise the sex attractant of the cotton boll weevil (Anthonomus grandis). Racemic grandisol was synthesized in eight steps and featured a microwave-assisted RCEYM as a key reaction sequence. Among the ten different catalysts tested, HG-2 showed the best result in the cyclisation of 199 (Scheme 55). ${ }^{110}$

Scheme 55. Synthesis of pheromone of Anthonomus grandis (201) (TBDPS = tertbutyldiphenylsilyl)

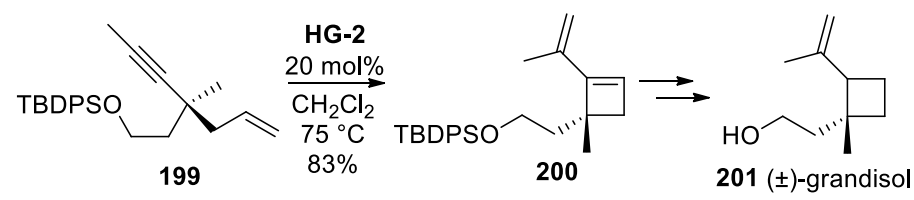

A CEM using ethylene (120) and 202 provided 203 which elaborated to 204, a component of the reproductive regulating queen ant pheromone (Scheme 56). ${ }^{11}$

Scheme 56. Synthesis of pheromone of queen ant (204)

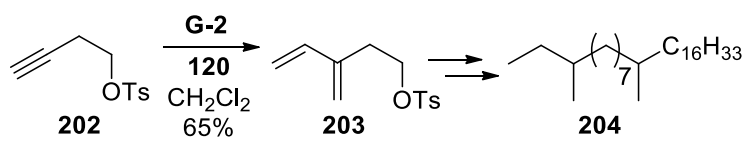




\section{Conclusion}

This article summarizes the most relevant work in the area of semiochemical synthesis that features olefin metathesis as the key reaction step.

Semiochemicals are chemicals that insects use for communication and they have long been known to be important to the behaviour of insects. Thus, they can be used as biopesticides and tend to pose fewer risks than conventional pesticides. These compounds can attract insect pests to the traps and interfere with mating. The disruption of the mating pattern is achieved by application of a biopesticide to the fields in order to confuse mating pests by overloading their sensory receptors. Many of the pheromone preparations over the past decades were accomplished by classical organic preparation techniques; however, there has been considerable effort recently to implement cost-effective chemical processes to achieve economically profitable and environmentally benign procedures.

Olefin metathesis has evolved into an important transformation in recent decades and has been effectively applied to the synthesis of semiochemicals and the creation of innovative materials in the field of green chemistry, especially in oleochemistry.

The importance of olefin metathesis to the total synthesis of semiochemicals is obvious from the large number of successful examples presented in this review. Based on in this work, some interesting observation can be highlighted. (1) By using metathesis reactions for pheromone synthesis, new and/or shorter reaction pathways can be achieved. (2) Stereoselective synthesis is also now possible with the development of novel and improved catalysts that offer $Z$ and $E$ olefin selectivity. (3) Green chemical technologies may be developed by metathesis reactions that utilize renewable, alkenyl feedstock. (4) Olefin metathesis such as ROCM and ROMP reactions 
can have high atom economy that may reach $100 \%$. (5) Olefin metathesis opens up new possibilities in total synthesis.

This review also highlights industrial applications of olefin metathesis as judged from the large number of patents, in addition to academic applications, emphasizing the importance and the development of the topic to practitioners. Continued research on these synthesizes and catalysts should assist the development of new and exciting value-added chemical products.

\section{AUTHOR INFORMATION}

\section{Corresponding Author}

*Robert Tuba, e-mail: tuba.robert@ttk.mta.hu, Paul T.Anastas, e-mail: paul.anastas@yale.edu

Institute of Materials and Environmental Chemistry, Research Centre for Natural Sciences, Hungarian Academy of Sciences Magyar tudósok körútja 2., 1519 Budapest, P.O. Box 286.

\section{Author Contributions}

The manuscript was written through the contributions of all authors. All authors have given approval to the final version of the manuscript. $\$$ These authors contributed equally. (match statement to author names with a symbol)

\section{ACKNOWLEDGMENT}

We thank the Hungarian Academy of Sciences and National Research, Development and Innovation Office (NKFIH) for financial support under Grant Nos. OTKA NN 117986. The financial support of ENOPACK Ltd. is highly appreciated. 


\section{REFERENCES}

(1) Pretty, J. N. The Pesticide Detox: Towards a More Sustainable Agriculture; Earthscan: London, 2005.

(2) Khater, H. F. Prospect of botanical biopesticides in insect pest management. Pharmacol. 3 2012, 12, 641-656.

(3) Khater, H. F. Ecosmart Biorational Insecticides: Alternative Insect Control Strategies. In Insecticides - Advances in Integrated Pest Management; Perveen, D. F., Ed.; InTech: Rijeka, 2012; pp 17-60.

(4) Wyatt, T. D. Pheromones and Animal Behaviour: Communication by Smell and Taste; Cambridge University Press: Cambridge, 2003.

(5) Howse, P. E.; Jones, O. T.; Stevens, I. D. R. Insect Pheromones and their Use in Pest Management; Chapman \& Hall: New York, 1998.

(6) Welter, S. C.; Pickel, C.; Millar, J. G.; Cave, F.; Steenwyk, R. A. Van; Dunley, J. Pheromone mating disruption offers selective management options for key pests. Calif. Agric. 2005, 59 (1), 16-22.

(7) Mol, J. C. Industrial applications of olefin metathesis. J. Mol. Catal. A Chem. 2004, 213 (1), $39-45$.

(8) Hoveyda, A. H.; Zhugralin, A. R. The remarkable metal-catalysed olefin metathesis reaction. Nature 2007, 450 (7167), 243-251.

(9) Mol, J. C. Application of olefin metathesis in oleochemistry: an example of green chemistry. 
Green Chem. 2002, 4 (1), 5-13.

(10) Calderon, N.; Ofstead, E. A.; Ward, J. P.; Judy, W. A.; Scott, K. W. Olefin metathesis. I. Acyclic vinylenic hydrocarbons. J. Am. Chem. Soc. 1968, 90 (15), 4133-4140.

(11) Malcolmson, S. J.; Meek, S. J.; Sattely, E. S.; Schrock, R. R.; Hoveyda, A. H. Highly efficient molybdenum-based catalysts for enantioselective alkene metathesis. Nature 2008, 456 (7224), 933-937.

(12) Jiang, A. J.; Zhao, Y.; Schrock, R. R.; Hoveyda, A. H. Highly Z-selective metathesis homocoupling of terminal olefins. J. Am. Chem. Soc. 2009, 131 (46), 16630-16631.

(13) Ondi, L.; Nagy, G. M.; Czirok, J. B.; Bucsai, A.; Frater, G. E. From Box to Bench: AirStable Molybdenum Catalyst Tablets for Everyday Use in Olefin Metathesis. Org. Process Res. Dev. 2016, 20 (10), 1709-1716.

(14) Ondi, L.; Mehdi, H.; Wampler, K. M.; Meinhold, P.; Coelho, P.; Bui, V. Production of fatty olefin derivatives via olefin metathesis. WO2017087710A2, 2017.

(15) Corrêa da Costa, R.; Gladysz, J. A. Fluorous phase-transfer activation of catalysts: application of a new rate-enhancement strategy to alkene metathesis. Chem. Commun. 2006, 2619-2621.

(16) Xi, Z.; Bazzi, H. S.; Gladysz, J. A. Analogs of Grubbs' second generation catalyst with hydrophilic phosphine ligands: Phase transfer activation of ring closing alkene metathesis. Org. Lett. 2011, 13 (23), 6188-6191.

(17) Anastas, P. T. .; Warner, J. C. Green Chemistry: Theory and Practice; Oxford University 
Press: New York, 1998.

(18) Hagström, Å. K.; Wang, H. L.; Liénard, M. A.; Lassance, J. M.; Johansson, T.; Löfstedt, C. A moth pheromone brewery: Production of (Z)-11-hexadecenol by heterologous coexpression of two biosynthetic genes from a noctuid moth in a yeast cell factory. Microb. Cell Fact. 2013, 12 (1), 1-11.

(19) Siau, W.; Zhang, Y.; Zhao, Y. Stereoselective Synthesis of Z -Alkenes. In Topics in Current Chemistry; Wang, J., Ed.; Springer-Verlag Berlin Heidelberg: Berlin, 2012; Vol. 327, pp $33-58$.

(20) Mathers, R. T.; McMahon, K. C.; Damodaran, K.; Retarides, C. J.; Kelley, D. J. Ringopening metathesis polymerizations in D-limonene: A renewable polymerization solvent and chain transfer agent for the synthesis of alkene macromonomers. Macromolecules 2006, 39 (26), 8982-8986.

(21) Ngo, H. L.; Foglia, T. A. Synthesis of long chain unsaturated- $\alpha, \omega$-dicarboxylic acids from renewable materials via olefin metathesis. JAOCS, J. Am. Oil Chem. Soc. 2007, 84 (8), 777784.

(22) Djigoué, G. B.; Meier, M. A. R. Improving the selectivity for the synthesis of two renewable platform chemicals via olefin metathesis. Appl. Catal. A Gen. 2009, 368 (1-2), 158-162.

(23) Mathers, R. T.; Shreve, M. J.; Meyler, E.; Damodaran, K.; Iwig, D. F.; Kelley, D. J. Synthesis and polymerization of renewable 1,3-cyclohexadiene using metathesis, isomerization, and cascade reactions with late-metal catalysts. Macromol. Rapid Commun. 2011, 32 (17), 1338-1342. 
(24) Akintayo, C. O.; Mutlu, H.; Kempf, M.; Wilhelm, M.; Meier, M. A. R. Acyclic triene metathesis polymerization of plukenetia conophora oil: Branched polymers by direct polymerization of renewable resources. Macromol. Chem. Phys. 2012, 213 (1), 87-96.

(25) Spiccia, N.; Border, E.; Illesinghe, J.; Jackson, W.; Robinson, A. Preparation of a nylon-11 precursor from renewable canola oil. Synth. 2013, 45 (12), 1683-1688.

(26) Bilel, H.; Hamdi, N.; Zagrouba, F.; Fischmeister, C.; Bruneau, C. Terminal conjugated dienes via a ruthenium-catalyzed cross-metathesis/ elimination sequence: Application to renewable resources. Catal. Sci. Technol. 2014, 4 (7), 2064-2071.

(27) Rossi, R. Insect Pheromones; I. Synthesis of Achiral Components of Insect Pheromones. Synthesis (Stuttg). 1977, 12, 817-836.

(28) Randall, M. L.; Snapper, M. L. Selective olefin metatheses - New tools for the organic chemist: A review. J. Mol. Catal. A Chem. 1998, 133 (1-2), 29-40.

(29) Levisalles, J.; Villemin, D. Metathese d'acetates d'alcohls $\omega$-insatures. Tetrahedron 1980, $36,3181-3185$.

(30) Baker, R.; Crimpnin, M. J. The tungsten catalysed metathesis of $\omega$-olefinic esthers. Tetrahedron Lett. 1977, 441-442.

(31) Banasiak, D. S. Insect Pheromones. J. Mol. Catal. 1985, 28, 107-115.

(32) Bykov, V. I.; Butenko, T. A.; Finkel'shtein, E. S.; Petrovskii, P. V.; Vdovin, V. M. Preparation of pheromone components by cometathesis reactions in the presence of $\mathrm{MoCl}_{5} / \mathrm{SiO}_{2} / \mathrm{R}_{4} \mathrm{Sn}$ Catalyst. Bull. Acad. Sci. USSR Div. Chem. Sci. 1988, 37 (7), 1397-1400. 
(33) Bykov, V. I.; Butenko, T. A.; Finkel'shtein, E. S.; Henderson, P. T. Synthesis of monoene pheromone components having a double bond in positions 6-11 using cometathesis of cycloolefins with $\alpha$-olefins. J. Mol. Catal. 1994, 90 (1-2), 111-116.

(34) Kuepper, F.; Streck, R. Synthesis of insect pheromones using metathesis catalysts. ChemZtg. 1975, 99, 464-465.

Bykov, V. I.; Butenko, T. A.; E. Finkelshtein, E. S. Stereo- and regioselectivity of the catalytic system MoCI5/SiO2-SnMe 4 in the reaction of metathesis and cometathesis of olefins and their functional derivatives. Bull. Acad.Sci. USSR 1990, 39 (1), 151-155.

(36) Finkel'shtein, E. S.; Bykov, V. I.; Portnykh, E. B. The olefin metathesis reaction - a versatile tool for fine organic synthesis. J. Mol. Catal. 1992, 76 (1-3), 33-52.

(37) Scholl, M.; Trnka, T. M.; Morgan, J. P.; Grubbs, R. H. Increased ring closing metathesis activity of ruthenium-based olefin metathesis catalysts coordinated with imidazolin-2ylidene ligands. Tetrahedron Lett. 1999, 40 (12), 2247-2250.

(38) Pederson, R. L.; Grubbs, R. H. Biologically active compounds by catalytic olefin metathesis. US5916983A, 1999.

(39) Pederson, R. L.; Grubbs, R. H. Synthesis of 5-decenylacetate and other pheromone components. US6215019B1, 2001.

(40) Millar, J. G.; Rice, R. E. Reexamination of the female sex pheromone of the peach twig borer: field screening of minor constituents of pheromone gland extracts and of pheromone analogs. J. Econ. Entomol. 1992, 85 (5), 1709-1716. 
(41) Millar, J. G.; Rice, R. E. 5-Decyn-1-yl acetate: Powerful antagonist of peach twig borer (Lepidoptera: Gelechiidae) sex pheromone. J. Econ. Entomol. 1996, 89 (1), 131-133.

(42) Pederson, R. L.; Fellows, I. M.; Ung, T. A.; Ishihara, H.; Hajela, S. P. Applications of olefin cross metathesis to commercial products. Adv. Synth. Catal. 2002, 344 (6-7), 728-735.

(43) Hill, A. S.; Roelofs, W. L. Sex pheromone components of the omnivorous leafroller moth, Platynota stultana. J. Chem. Ecol.1975, 1 (1), 91-99.

(44) Balla, Á.; Al-Hashimi, M.; Hlil, A.; Bazzi, H. S.; Tuba, R. Ruthenium-Catalyzed Metathesis of Conjugated Polyenes. ChemCatChem 2016, 8 (18), 2865-2875.

(45) Kovács, E.; Sághy, P.; Turczel, G.; Tóth, I.; Lendvay, G.; Domján, A.; Anastas, P. T.; Tuba, R. Metathesis of renewable polyene feedstocks - Indirect evidences of the formation of catalytically active ruthenium allylidene species. J. Organomet. Chem. 2017, 847, 213-217.

(46) Kovács, E.; Turczel, G.; Szabó, L.; Varga, R.; Tóth, I.; Anastas, P. T.; Tuba, R. Synthesis of 1,6-Hexandiol, Polyurethane Monomer Derivatives via Isomerization Metathesis of Methyl Linolenate. ACS Sustain. Chem. Eng. 2017, 5 (12), 11215-11220.

(47) Turczel, G.; Kovács, E.; Csizmadia, E.; Nagy, T.; Tóth, I.; Tuba, R. One-pot Synthesis of 1,3-Butadiene and 1,6-Hexandiol Derivatives from Cyclopentadiene (CPD) via Tandem Olefin Metathesis Reactions. ChemCatChem 2018, 10, 4884-4891.

(48) Vyshnavi, Y.; Prasad, R. B. N.; Karuna, M. S. L. Metathesis of tobacco fatty acid methyl esters: Generation of industrially important platform chemicals. Ind. Crops Prod. 2013, 50, 701-706. 
(49) Prasad, K. R.; Anbarasan, P. Enantiodivergent Synthesis of Both Enantiomers of Gypsy Moth Pheromone Disparlure. J. Org. Chem. 2007, 72, 3155-3157.

(50) Kim, S. G. Concise total synthesis of (+)-disparlure and its trans-isomer using asymmetric organocatalysis. Synthesis (Stuttg). 2009, No. 14, 2418-2422.

(51) Kim, S. G.; Park, T. H.; Kim, B. J. Efficient total synthesis of (+)-exo-, (-)-endo-brevicomin and their derivatives via asymmetric organocatalysis and olefin cross-metathesis. Tetrahedron Lett. 2006, 47 (36), 6369-6372.

(52) Van Zijl, A. W.; Szymanski, W.; López, F.; Minnaard, A. J.; Feringa, B. L. Catalytic enantioselective synthesis of vicinal dialkyl arrays. J. Org. Chem. 2008, 73 (18), 69947002.

(53) Mori, K. Pheromone synthesis. Part 240: Cross-metathesis with Grubbs I (but not Grubbs II) catalyst for the synthesis of (R)-trogodermal (14-methyl-8-hexadecenal) to study the optical rotatory powers of compounds with a terminal sec-butyl group. Tetrahedron $\mathbf{2 0 0 9}$, 65 (19), 3900-3909.

(54) Mori, K. Synthesis of all the stereoisomers of 6-methyl-2-octadecanone, 6,14-dimethyl-2octadecanone, and 14-methyl-2-octadecanone, the components of the female-produced sex pheromone of a moth, Lyclene dharma dharma. Tetrahedron 2009, 65 (14), 2798-2805.

(55) Mori, K.; Tashiro, T. Synthesis of all the four stereoisomers of (1'S)-1-ethyl-2methylpropyl 3,13-dimethylpentadecanoate, the major component of the sex pheromone of Paulownia bagworm, Clania variegata. Tetrahedron Lett. 2009, 50 (26), 3266-3269. 
(56) Mori, K.; Tashiro, T.; Zhao, B.; Suckling, D. M.; El-Sayed, A. M. Pheromone synthesis. Part 243: Synthesis and biological evaluation of (3R,13R,1'S)-1'-ethyl-2'-methylpropyl 3,13-dimethylpentadecanoate, the major component of the sex pheromone of Paulownia bagworm, Clania variegata, and its stereoisomers. Tetrahedron 2010, 66 (14), 2642-2653.

(57) Quinn, K. J.; Curto, J. M.; McGrath, K. P.; Biddick, N. A. Facile synthesis of (-)-6-acetoxy5-hexadecanolide by size-selective ring-closing/cross metathesis. Tetrahedron Lett. 2009, $50(51), 7121-7123$.

(58) Schmidt, B.; Petersen, M. H.; Braun, D. Bidirectional Synthesis of 6-Acetoxy-5hexadecanolide, the Mosquito Oviposition Pheromone of Culex quinquefasciatus, from a C2-Symmetric Building Block Using Olefin Metathesis Reactions. J. Org. Chem. 2018, 83 (3), 1627-1633.

(59) Virolleaud, M.-A.; Bressy, C.; Piva, O. A straightforward synthesis of (E)- $\delta$-alkenyl- $\beta, \gamma-$ unsaturated $\delta$-lactones by a tandem ring-closing/cross-coupling metathesis process. Tetrahedron Lett. 2003, 44, 8081-8084.

(60) Virolleaud, M. A.; Piva, O. Domino ring-closing metathesis/intramolecular transfer of an alkenyl subunit: A direct formation of functionalized butenolides and pyrones from $\alpha, \beta$ and $\beta, \gamma$-unsaturated esters. Synlett 2004, No. 12, 2087-2090.

(61) Wang, S. Y.; Song, P.; Chin, Y. J.; Loh, T. P. A general strategy for the introduction of stereogenic centers bearing a methyl group: Total synthesis of sex pheromones. Chem. - An Asian J. 2011, 6 (2), 385-388.

(62) Storvick, J. M.; Ankoudinova, E.; King, B. R.; Van Epps, H.; O’Neil, G. W. Total synthesis 
of haminol A: An analysis of vinylpyridine metathesis reactivity. Tetrahedron Lett. 2011, $52(44), 5858-5861$.

(63) Hollister, K. A.; Conner, E. S.; Zhang, X.; Spell, M.; Bernard, G. M.; Patel, P.; De Carvalho, A. C. G. V; Butcher, R. A.; Ragains, J. R. Ascaroside activity in Caenorhabditis elegans is highly dependent on chemical structure. Bioorganic Med.Chem. 2013, 21 (18), 5754-5769.

(64) Shikichi, Y.; Mori, K. Metathesis-Mediated Synthesis of (R)-10-Methyl-2-tridecanone, the Southern Corn Rootworm Pheromone. Biosci. Biotechnol. Biochem. 2012, 76 (2), 407-409.

(65) Kranidiotis, N. S.; Grammatoglou, C. E.; Gallos, J. K. A new short synthesis of ( \pm )-olean through cross metathesis. Heterocycles 2018, 96 (8), 1441-1444.

(66) Chatterjee, A. K.; Choi, T. L.; Sanders, D. P.; Grubbs, R. H. A general model for selectivity in olefin cross metathesis. J. Am. Chem. Soc. 2003, 125 (37), 11360-11370.

(67) Morrill, C.; Grubbs, R. H. Synthesis of Functionalized Vinyl Boronates via RutheniumCatalyzed Olefin Cross-Metathesis and Subsequent Conversion to Vinyl Halides. J. Org. Chem. 2003, 68 (15), 6031-6034.

(68) Endo, K.; Grubbs, R. H. Chelated ruthenium catalysts for Z -selective olefin metathesis. $J$. Am. Chem. Soc. 2011, 133 (22), 8525-8527.

(69) Keitz, B. K.; Endo, K.; Patel, P. R.; Herbert, M. B.; Grubbs, R. H. Improved Ruthenium Catalysts for Z -Selective Olefin Metathesis. J. Am. Chem. Soc. 2012, 134, 693-699.

(70) Subbaraman, A. S.; Mithran, S.; Mamdapur, V. R. An expedient synthesis of the sugarcane borer pheromone components. Molecules 1998, 3 (2), 35-40. 
(71) Herbert, M. B.; Marx, V. M.; Pederson, R. L.; Grubbs, R. H. Concise syntheses of insect pheromones using Z-Selective cross metathesis. Angew. Chemie - Int. Ed. 2013, 52 (1), $310-314$.

(72) Rosebrugh, L., E.; Herbert, M., B.; Marx, V., M.; Keitz, B., K.; Grubbs, R., H. Z-Selective metathesis catalysts. WO 2014/093687 Al, 2014.

(73) Ortiz, A.; Quesada, A.; Sanchez, A. Potential for use of synthetic sex pheromone for mating disruption of the olive pyralid moth, Euzophera pinguis. J. Chem. Ecol. 2004, 30 (5), 9911000.

(74) Hornyánszky, G.; Rohály, J.; Novák, L. Facile synthesis of mill moth’s sex pheromone components. Synth. Commun. 2008, 38 (10), 1533-1540.

(75) Luo, S. X.; Cannon, J. S.; Taylor, B. L. H.; Engle, K. M.; Houk, K. N.; Grubbs, R. H. ZSelective Cross-Metathesis and Homodimerization of 3E-1,3-Dienes: Reaction Optimization, Computational Analysis, and Synthetic Applications. J. Am. Chem. Soc. 2016, 138 (42), 14039-14046.

(76) Bykov, V. I.; Finkelshtein, E. S. Synthesis of natural compounds via the cycloolefin cometathesis with $\alpha$-olefins. J. Mol. Catal. A Chem. 1998, 133 (1-2), 17-27.

(77) Bykov, V. I.; Butenko, T. A.; Egupova, E. V.; Finkelshtein, E. S. New synthesis of (Z)-5and (Z)-7-monoene components of insect sex pheromones of the Lepidoptera order. Russ. Chem. Bull. 2000, 49 (7), 1301-1304.

(78) Kuwahara, Y.; Nakamura, S. (Z)-5- and (E)-5-Undecenoic Acid : Identification of the Sex 
Pheromone of the Varied Carpet Beetle, Anthrenus verbasci L. (Coleoptera : Dermestidae). Appl. Entomol. Zool. 1985, 20 (3), 354-356.

(79) Harada, H.; Mori, K. Simple Synthesis of a Mixture of ( $E$ )- and ( $Z$ )-5-Undecenoic Acid, Sex Pheromone of the Varied Carpet Beetle. Agric. Biol. Chem. 1989, 53 (5), 1439-1440.

(80) Bykov, V. I.; Goletiani, A. R.; Butenko, T. A.; Finkelshtein, E. S. A new synthesis of (Z,E)undec-5-enoic acids, the sex pheromone of the varied carpet beetle Anthrenus verbasci. Russ. Chem. Bull. 2004, 53 (11), 2650-2652.

(81) Tallarico, J. A.; Randall, M. L.; Snapper, M. L. Selectivity in ring-opening metathesis. Tetrahedron 1997, 53 (48), 16511-16520.

(82) Hartung, J.; Grubbs, R. H. Catalytic, enantioselective synthesis of 1,2-anti-diols by asymmetric ring-opening/cross-metathesis. Angew. Chemie - Int. Ed. 2014, 53 (15), 38853888.

(83) Fürstner, A.; Langemann, K. Conformationally Unbiased Macrocyclization Reactions by Ring Closing Metathesis. J. Org. Chem. 1996, 61 (d), 3942-3943.

(84) Fürstner, A.; Langemann, K.; Kindler, N. Synthesis of functionalized macrocycles by ring closing metathesis. US5936100A, 1999.

(85) Peram, P. S.; Vences, M.; Schulz, S. A synthetic dodecanolide library for the identification of putative semiochemicals emitted by mantellid frogs. Org. Biomol. Chem. 2017, 15, 6967-6977.

(86) Burke, S. D.; Müller, N.; Beaudry, C. M. Desymmetrization by ring-closing metathesis 
leading to 6,8-dioxabicyclo[3.2.1]octanes: a new route for the synthesis of (+)-exo- and endo-brevicomin. Org. Lett. 1999, 1 (11), 1827-1829.

(87) Scholl, M.; Grubbs, R. H. Total Synthesis of (-)- and (+)-Frontalin v/a Ring-Closing Metathesis. Tetrahedron Lett. 1999, 40, 1425-1428.

(88) Ramachandran, P. V.; Reddy, M. V. R.; Brown, H. C. Asymmetric synthesis of goniothalamin, hexadecanolide, massoia lactone, and parasorbic acid via sequential allylboration-esterification ring-closing metathesis reactions. Tetrahedron Lett. $\mathbf{2 0 0 0 ,} 41$ (5), 583-586.

(89) Harbindu, A.; Sharma, B. M.; Kumar, P. Asymmetric routes to pentadec-1-en-4-ol: Application to the syntheses of aculeatins F and epi-F, (R)- and (S)-5-hexadecanolide and a formal synthesis of solenopsin. Tetrahedron Asymmetry 2013, 24 (5-6), 305-314.

(90) Ghosh, S. K.; Hsung, R. P.; Wang, J. Ketal-tethered ring-closing metathesis. An unconventional approach to constructing spiroketals and total synthesis of an insect pheromone. Tetrahedron Lett. 2004, 45 (28), 5505-5510.

(91) Ghosh, S. K.; Ko, C.; Liu, J.; Wang, J.; Hsung, R. P. A ketal-tethered RCM strategy toward the synthesis of spiroketal related natural products. Tetrahedron 2006, 62 (45), 1048510496.

(92) Matovic, R.; Ivkovic, A.; Manojlovic, M.; Tokic-vujosevic, Z.; Saicic, R. N.; Chemistry, F.; Uni, V. Ring Closing Metathesis/Fragmentation Route to (Z)-Configured Medium Ring Cycloalkenes. Total Synthesis of (+-)-Periplanone C. J. Org. Chem. 2006, 71, 9411-9419. 
(93) Prasad, K. R.; Anbarasan, P. Stereoselective synthesis of (-)-6-acetoxyhexadecanolide: a mosquito oviposition attractant pheromone. Tetrahedron Asymmetry 2007, 18 (20), 24792483.

(94) Park, Y.; Tae, J. Facile Synthesis of (-) -6-Acetoxy-5-hexadecanolide by Organocatalytic a -Oxygenation - Allylation - RCM Strategy. Synthesis (Stuttg). 2010, 21, 3627-3630.

(95) Hooper, A. M.; Dufour, S.; Willaert, S.; Pouvreau, S.; Pickett, J. A. Synthesis of (2S,7S)dibutyroxynonane, the sex pheromone of the orange wheat blossom midge, Sitodiplosis mosellana (Géhin) (Diptera: Cecidomyiidae), by diastereoselective silicon-tethered ringclosing metathesis. Tetrahedron Lett. 2007, 48 (34), 5991-5994.

(96) Sabitha, G.; Fatima, N.; Reddy, E. V.; Yadav, J. S. Prins and RCM protocols for the synthesis of the pheromones of the giant white butterfly Idea leuconoe. Tetrahedron Lett. 2008, 49 (42), 6087-6089.

(97) Yildizhan, S.; van Loon, J.; Sramkova, A.; Ayasse, M.; Arsene, C.; ten Broeke, C.; Schulz, S. Aphrodisiac pheromones from the wings of the small cabbage white and large cabbage white butterflies, Pieris rapae and Pieris brassicae. ChemBioChem 2009, 10 (10), 16661677.

(98) Dufour, S.; Castets, P.; Pickett, J. A.; Hooper, A. M. A diastereoselective synthesis of (1SR,3SR,7RS)-3-methyl- $\alpha$-himachalene, the sex pheromone of the sandfly, Lutzomyia longipalpis (Diptera: Psychodidae). Tetrahedron 2012, 68 (25), 5102-5108.

(99) Kurhade, S.; Siddaiah, V.; Bhuniya, D.; Reddy, D. S. Synthesis of a sex pheromone of the longtailed mealybug, pseudococcus longispinus 1. Synth. 2013, 45 (12), 1689-1692. 
(100) Ramesh, R.; Swaroop, P. S.; Gonnade, R. G.; Thirupathi, C.; Waterworth, R. A.; Millar, J. G.; Reddy, D. S. Syntheses and determination of absolute configurations and biological activities of the enantiomers of the longtailed mealybug pheromone. J. Org. Chem. 2013, $78(12), 6281-6284$.

(101) Mori, K. Pheromone synthesis. Part 260: Synthesis of ( \pm )-(anti-1,2-dimethyl-3methylenecyclopentyl)acetaldehyde, the racemate of the female-produced sex pheromone of the pineapple mealybug (Dysmicoccus brevipes), and its syn-isomer. Tetrahedron 2016, $72(41), 6578-6588$.

(102) Mori, K.; Tabata, J. Pheromone synthesis. Part 262: Determination of the absolute configuration of the female sex pheromone [(1S,2S)-(-)-(1,2-dimethyl-3methylenecyclopentyl) acetaldehyde] of the pineapple mealybug (Dysmicoccus brevipes) by synthesis coupled with X-ray analys. Tetrahedron 2017, 73 (46), 6530-6541.

(103) Fürstner, A.; Seidel, G. Ring-closing metathesis of functionalized acetylene derivatives: A new entry into cycloalkynes. Angew. Chemie - Int. Ed. 1998, 37 (12), 1734-1736.

(104) Fürstner, A.; Davies, P. W. Alkyne metathesis. Chem. Commun. 2005, No. 18, 2307-2320.

(105) Hötling, S.; Haberlag, B.; Tamm, M.; Collatz, J.; Mack, P.; Steidle, J. L. M.; Vences, M.; Schulz, S. Identification and synthesis of macrolide pheromones of the grain beetle oryzaephilus surinamensis and the frog spinomantis aglavei. Chem. - A Eur. J. 2014, 20 (11), 3183-3191.

(106) Hötling, S.; Bittner, C.; Tamm, M.; Dähn, S.; Collatz, J.; Steidle, J. L. M.; Schulz, S. Identification of a Grain Beetle Macrolide Pheromone and Its Synthesis by Ring-Closing 
Metathesis Using a Terminal Alkyne. Org. Lett. 2015, 17 (20), 5004-5007.

(107) Lee, H. Y.; Gyu Kim, B.; Snapper, M. L. A stereoselective enyne cross metathesis. Org. Lett. 2003, 5 (11), 1855-1858.

(108) Debleds, O.; Campagne, J. M. 1, 5-Enyne Metathesis. J. Am. Chem. Soc. 2008, 130 (5), $1562-1563$.

(109) Villar, H.; Frings, M.; Bolm, C. Ring closing enyne metathesis: A powerful tool for the synthesis of heterocycles. Chem. Soc. Rev. 2007, 36 (1), 55-66.

(110) Graham, T. J. A.; Gray, E. E.; Burgess, J. M.; Goess, B. C. An efficient synthesis of ( \pm )grandisol featuring 1,5-enyne metathesis. J. Org. Chem. 2010, 75 (1), 226-228.

(111) Lee, J.; Lee, H.; Sohn, J. H. Reproductive regulating pheromones of queen ant: A short and versatile synthesis of 3,11-dimethylheptacosane. Bull. Korean Chem. Soc. 2011, 32 (9), $3213-3214$. 
Graphical Abstract:

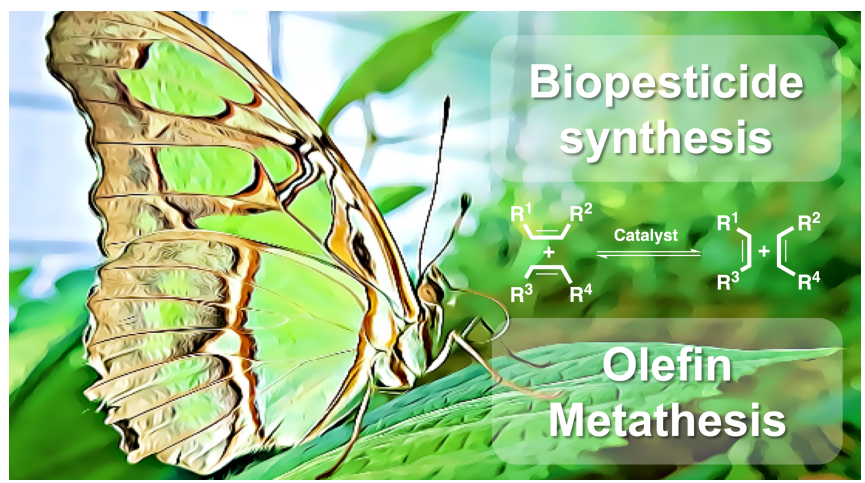




\section{Turczel Gábor - Hungarian Academy of Sciences}

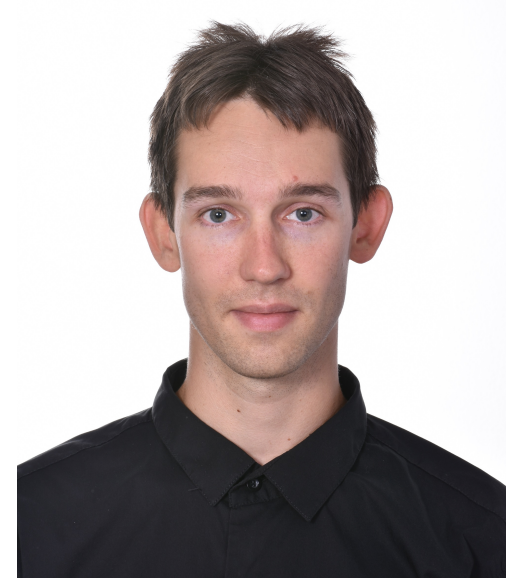

Turczel Gábor is a PhD student at the Green Chemistry Research Group at Research Centre for Natural Sciences, Hungarian Academy of Sciences (RCNS-HAS). He obtained his BSc in chemical engineering and MSc in pharmaceutical engineering from the Budapest University of Technology and Economics. His current research focuses on olefin metathesis and transition metal catalyzed semiochemical synthesis. 


\section{Ervin Kovács - Hungarian Academy of Sciences}

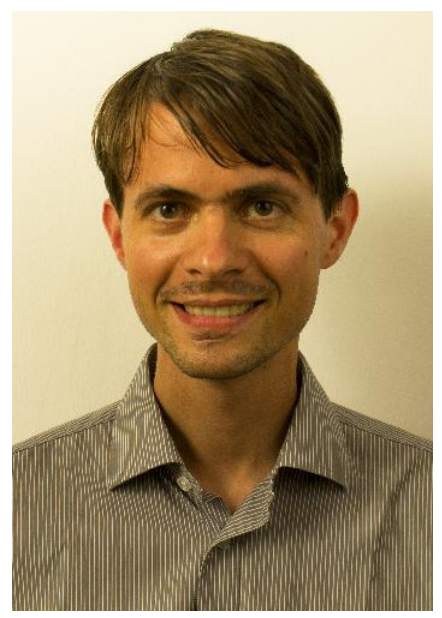

Ervin Kovács obtained his MSc (2008) and PhD (2015) degree from Budapest University of Technology and Economics under the guidance of Prof. Ferenc Faigl on the research field of superbases. During his PhD research he worked with Prof. Alessandro Mordini at University of Florenc in Italy in 2011. After his $\mathrm{PhD}$ he worked as an assistant research scientist at Organic Chemical Technology Research Group at Budapest University of Technology and Economics. In 2016 he joined the Green Chemistry Research Group at RCNS-HAS. His research focuses on the sustainable synthesis, involving transition-metal catalysis. Research areas include analytical, preparative organic and organometallic chemistry. He was awarded with Földi Zoltán Prize (2008) in organic chemistry and National Research, Development and Innovation Office (OTKA) Postdoctoral Excellence Award (2018). 


\section{Gabriella Merza - Hungarian Academy of Sciences}

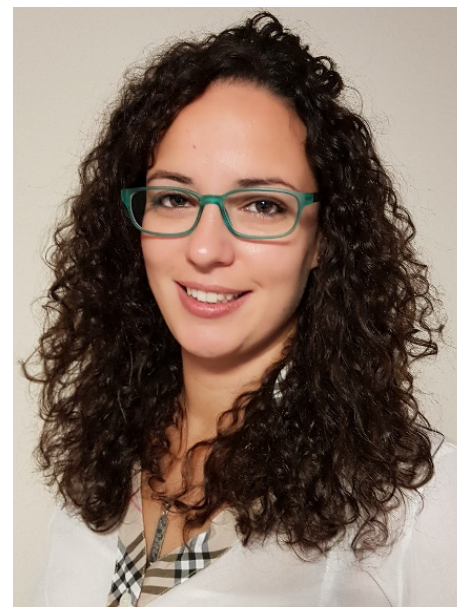

Gabriella Merza has obtained her MSc (2009) and PhD (2016) in Environmental Sciences from the University of Szeged, Hungary. She is currently working as a Postdoctoral Research Fellow at the Green Chemistry Research Group at RCNS-HAS. During her university studies she has worked with Professor Anna Corrias and Dr. Maria Francesca Casula at the Department of Chemistry, University of Cagliari, Italy. During her doctoral studies she was awarded by the National Excellence Program of Hungary in the field of research and innovation. Her research interests focus on green chemistry and well-defined biopolymer synthesis. 


\section{Philip Coish - Yale University}

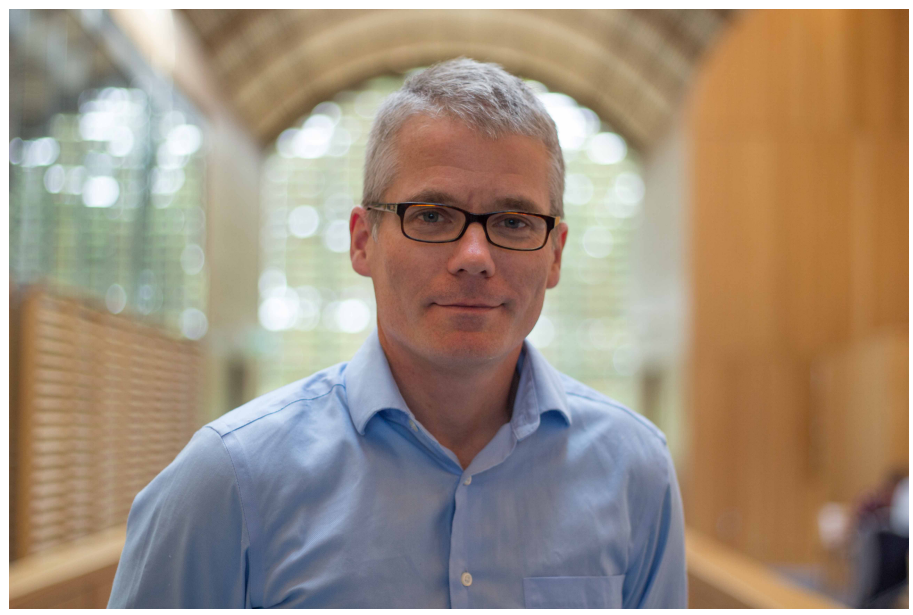

Program Manager, Center for Green Chemistry and Green Engineering at Yale. Phil is an experienced organic chemist and portfolio manager with a depth of knowledge and a record of accomplishment in multiple areas including green chemistry, medicinal chemistry, portfolio and project management, and biobusiness. He received his Ph.D. in synthetic organic chemistry from the University of British Columbia and was a post-doctoral fellow at the University of Pittsburgh. He has recently obtained a graduate certificate in Core Business Skills from Sacred Heart University. He started his professional career at Bayer Healthcare as a drug researcher, project leader, and portfolio manager. He then worked at Sepracor (now Sunovion) as an Associate Director where he managed the growth and development of the early discovery research portfolio. After Sepracor, he joined BioRelix, a start-up biotech where he served as Director of Chemistry. He is currently a program manager at the Center for Green Chemistry and Green Engineering at Yale. Phil has many roles at the Center, including operations, collaborations, and development. He has a keen interest in Green Chemistry and sustainability, and has been engaged in scientific writing and outreach within the field. 


\section{Paul T. Anastas - Yale University}

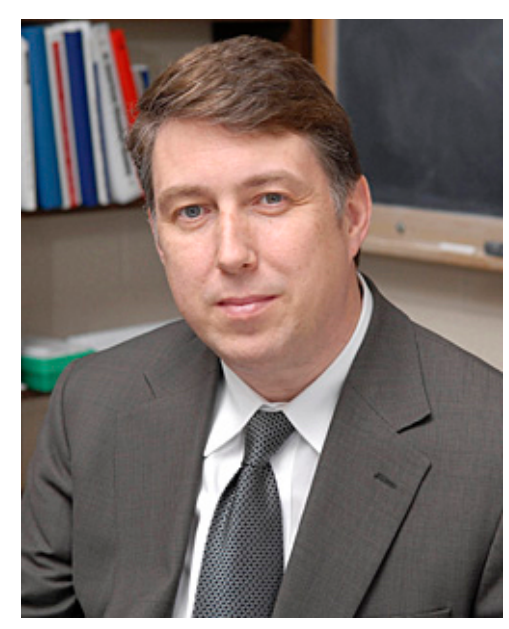

Professor Paul T. Anastas is on the faculty of Yale University with appointments in the Department of Chemistry, the School of Engineering and Applied Sciences, The School of Forestry and Environmental Studies, School of Medicine and the School of Management. He is widely known for his work in pioneering the field of Green Chemistry and has published 13 books on sustainable technology. He has experience in business (co-founded three companies), the NGO world (cofounded the Green Chemistry Institute), and government having served in the Administrations of the past three U.S. Presidents including serving in the White House Office of Science and Technology Policy in the Clinton and Bush Administrations and as Assistant Administrator and Chief Scientist at the U.S. Environmental Protection Agency in the Obama Administration.

Selected awards include: Heinz Award, Rachel Carson Prize, E. O. Wilson Prize, Emanuel Merck Medal 


\section{Robert Tuba - Hungarian Academy of Sciences}

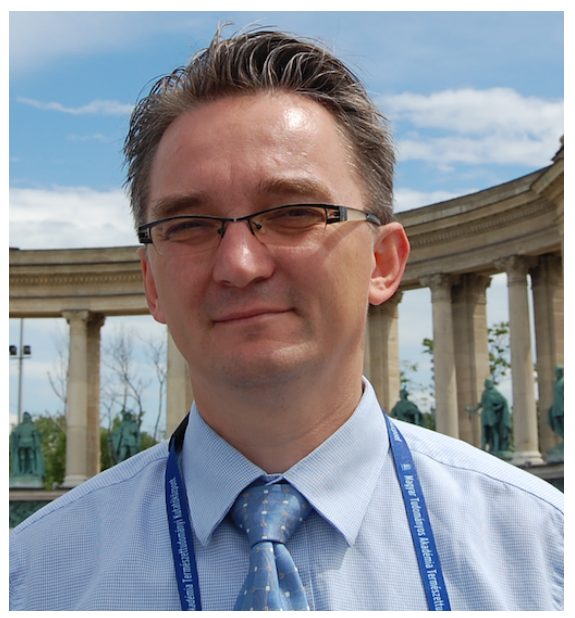

Robert Tuba was born in Fehérgyarmat, Hungary in 1974. He obtained his M.Sc. (1998) and Ph.D. (2003) degree from University of Veszprém (University of Pannonia) with Professor Ferenc Ungváry. After a postdoctoral study at Eötvös Lorándt University with Professor István T. Horváth he joined the research group of Professor John A. Gladysz at Friedrich Alexander University Erlangen-Nürnberg as Alexander von Humboldt research fellow. In 2007 he joined the GlaxoSmithKline Biologicals as process development supervisor. In 2011, he joined the Texas A\&M University at Qatar as assistant research scientists. He was visiting associate in chemistry in California Institute of Technology at the research group of Professor Robert H. Grubbs in 2013. He is currently Head of Green Chemistry Research Group at Institute of Materials and Environmental Chemistry, Research Centre for Natural Sciences, Hungarian Academy of Sciences (RCNS-HAS). 